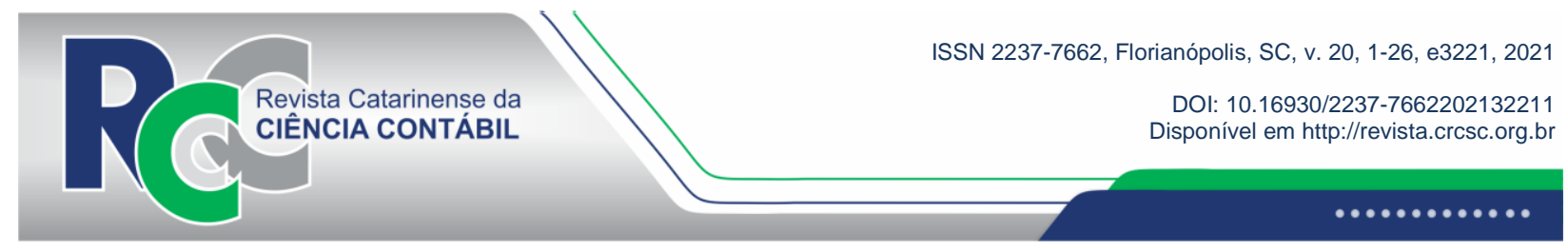

\title{
VARIÁVEIS INSTITUCIONAIS EXPLICATIVAS DO DESEMPENHO DE ESTUDANTES DE CIÊNCIAS CONTÁBEIS E ADMINISTRAÇ̃̃̃O
}

\author{
INSTITUTIONAL VARIABLES EXPLAINING THE PERFORMANCE OF \\ ACCOUNTING AND ADMINISTRATION STUDENTS
}

\author{
VITOR HIDEO NASU \\ Universidade de São Paulo. Endereço: Av. Prof. Luciano \\ Gualberto, 908 | Butantã | 05508-010 | São Paulo/SP | \\ Brasil. \\ (1) https://orcid.org/0000-0002-5176-6634 \\ vnasu@usp.br
}

\author{
BRENO GABRIEL DA SILVA \\ Universidade de São Paulo. Endereço: Av. Pádua Dias, \\ 235 | Agronomia | 13418-900 | Piracicaba/SP | Brasil. \\ (D) https://orcid.org/0000-0002-8322-9235 \\ brenogsilva@usp.br
}

\author{
YANA MIRANDA BORGES \\ Instituto Federal de Educação, Ciência e Tecnologia do \\ Amazonas. Endereço: Av. Sete de Setembro, 1975 | Centro \\ | 69020-120 | Manaus/AM | Brasil. \\ (D) https://orcid.org/0000-0002-1866-5524 \\ borges.yana@gmail.com
} BRIAN ALVAREZ RIBEIRO DE MELO
Universidade Estadual de Maringá. Endereço: Av.
Colombo, 5790 | Jd. Universitário | $87020-900$ |
Maringá/PR | Brasil.
(1) https://orcid.org/0000-0002-8217-114X
brian.rmelo@gmail.com

\section{RESUMO}

O objetivo deste estudo foi analisar a associação entre variáveis institucionais e o desempenho de estudantes de ciências contábeis e administração. Foram utilizados os microdados do Enade 2018, obtendo-se 152.491 observações válidas. O desempenho foi mensurado de três formas: desempenho final, desempenho na prova de formação geral e desempenho na prova de componente específico. Ademais, foram consideradas as seguintes variáveis institucionais: organização acadêmica, região, modalidade e turno. Os dados foram examinados a partir de modelos de regressão Box Cox Cole Green (BCCG) com zeros ajustados. A partir dos resultados, concluiu-se que as variáveis institucionais foram relevantes para explicar o desempenho. Especificamente, destaca-se que os estudantes matriculados em centros federais de educação tecnológica tiveram desempenho superior aos das outras formas de organização acadêmica. Outro ponto é que os alunos da região Norte performaram pior do que o das outras regiões de modo geral. Todavia, superaram os alunos da região Centro-Oeste nas questões de formação geral. Quanto à modalidade de ensino, verificou-se que alunos do ensino presencial apresentaram performance superior a dos estudantes do ensino a distância (EaD). E os alunos do turno integral tiveram melhores performances de modo geral. Como implicações, aponta-se que as instituições que oferecem cursos de contabilidade e administração na região Norte podem querer aprimorar a qualidade do ensino, assim como as do Centro-Oeste podem querer fazê-lo em relação ao ensino de formação geral. Da mesma forma, o ensino da modalidade EaD pode ser aprimorado e a oferta de cursos em período integral pode ser pensada e, potencialmente, implantada.

Palavras-chave: Variáveis institucionais. Desempenho acadêmico. Aprendizagem. Negócios. BCCG.

Editado em português e inglês. Versão original em português.

Recebido em 3/11/2021. Revisado em 13/12/2021. Aceito em 14/12/2021 pelos Prof. Dr. Sérgio Murilo Petri (Editor-Chefe) e Prof. Dr. Sandro Vieira Soares (Editor Adjunto). Publicado em 23/12/2021.

Copyright (C) 2021 RCCC. Todos os direitos reservados. É permitida a citação de parte de artigos sem autorização prévia, desde que identificada a fonte. 


\begin{abstract}
The aim of this study was to analyze the association between institutional variables and the performance of Accounting and Administration students. The microdata of Enade 2018 were used, obtaining 152,491 valid observations. Performance was measured in three ways: final performance, performance in the general training test and performance in the specific component test. In addition, the following institutional variables were considered: academic organization, region, modality and shift. The data were examined using zero adjusted Box Cox Cole Green (BCCG) regression models. The results indicated the institutional variables were relevant to explain the performance. Specifically, it was staked students enrolled in federal centers of technological education had superior performance than the other forms of academic organization. Another relevant point was the students in the North region performed worse than other regions in general. However, they outdid the students from Central-East region in the issues of general training. Regarding the teaching modality, it was found that students of face-toface teaching presented higher performance than the distance learning students (DL). And the full-time students had better performances overall. As implications, it is pointed out that institutions offering Accounting and Administration courses in the Northern region may want to improve the quality of education, as well as those of the Centre-Western shall want to do so in relation to general training education. Similarly, the teaching on the DL modality can be improved and the offer of full-time courses can be thought of and potentially implemented.
\end{abstract}

Keywords: Institutional variables. Academic performance. Learning. Business. BCCG.

\title{
1 INTRODUÇÃO
}

O desempenho do estudante é um importante construto acadêmico porque fornece indicação sobre a aprendizagem discente. A sua mensuração é um dos pontos fundamentais por determinar quem avança ou quem repete a disciplina, para quem deve ser concedida bolsa de estudos, para quem são destinadas as vagas de intercâmbio, quem ingressa na pós-graduação e assim por diante. $\mathrm{O}$ desempenho acadêmico é utilizado como critério de seleção para uma série de atividades e políticas institucionais, bem como pode ser usado na análise curricular em entrevistas de emprego. Usualmente, alunos com históricos escolares mais bem qualificados tendem a obter tais vantagens.

A mensuração do desempenho estudantil também é útil e necessária para que se possa verificar progressos e retrocessos da aprendizagem ao longo do tempo. Medidas didáticas e disciplinares podem se aplicar aos estudantes dependendo do que as análises do seu desempenho permitirem concluir. Miranda, Lemos, Oliveira e Ferreira (2015) notam que há distintas mensurações do desempenho do estudante, incluindo a nota de uma avaliação, a nota de uma disciplina, a nota média do período, a média geral acumulada pura ou ajustada e avaliações externas às instituições de educação. Independentemente da medida de desempenho que se utilize, o propósito é de se avaliar a capacidade demonstrada pelo aluno na realização de certa tarefa a partir de critérios bem definidos.

Por sua relevância e utilidade na área educacional, pesquisadores buscam entender quais e como as variáveis estão associadas ao desempenho do estudante de forma a otimizá-lo (Ahinful, Tauringana, Bansah \& Essuman, 2019; Byrne \& Flood, 2008; Caetano, Cardoso, Miranda, \& Freitas, 2015; Nasu \& Sasso, 2021; Rodrigues, Miranda, Resende, \& Pereira, 2016). Entender os fatores que estão associados ao desempenho acadêmico pode assistir alunos, professores, diretores acadêmicos e políticos educacionais a implantarem ou ajustarem políticas, práticas e planos pedagógicos de modo a aumentar a aprendizagem do aluno. 
$\mathrm{Na}$ área de negócios, as variáveis que determinam o desempenho discente podem ser classificadas em três grandes grupos: corpo discente (CDI); corpo docente (CDO); e da instituição de ensino superior (IES) (Miranda et al., 2015; Rodrigues et al., 2016). No grupo CDI estão as variáveis do estudante, tais como sexo, idade e status civil. No grupo CDO, compreendem-se variáveis como titulação, regime de trabalho e experiência profissional do professor. Por fim, no grupo IES constam variáveis relacionadas à instituição, incluindo ambiente de estudo, infraestrutura e horário da disciplina, por exemplo. O estudo de Soares (2004, p. 96) mostra que até mesmo as variáveis de segurança ("existência de itens na escola como: ajuda da polícia, muros e cercas protetoras, controle de entrada e saída de alunos e de outras pessoas, sinais de depredação") e limpeza da escola ("índice atribuído pelo aplicador da prova à limpeza das salas de aula, banheiros, áreas de recreação e áreas externas") podem influenciar o desempenho do aluno.

Nos campos de administração e contabilidade (aqui sob um guarda-chuva mais amplo denominado de "área de negócios"), os profissionais lidam com diversos setores dentro das empresas e precisam ter uma visão global do seu funcionamento para tomadas de decisão apropriadas. Consequentemente, a sua formação acadêmica precisa ser sólida de tal sorte que esta perspectiva empresarial holística seja absorvida pelo estudante. Portanto, os professores de cursos da área de negócios possuem forte motivação para continuar analisando a performance de seus alunos e variáveis relacionadas. Na visão de Byrne e Flood (2008), quanto mais informações acerca dos fatores associados ao sucesso ou ao fracasso acadêmico, mais bem preparados os professores estão para apoiar e orientar os seus estudantes. Logo, o acompanhamento da aprendizagem do aluno, refletida no seu desempenho acadêmico, é crucial para o seu aprimoramento.

Esforços significativos têm sido empregados para compreender as variáveis associadas ao desempenho dos estudantes da área de negócios (Byrne \& Flood, 2008; Caetano et al., 2015; Gracia \& Jenkins, 2003; Mallmann, Nasu \& Domingues, 2021; Nasu \& Sasso, 2021; Pike, 1991; Rodrigues et al., 2016). Todavia, enquanto há forte concentração de trabalhos que investigam as variáveis dos grupos CDI e CDO, existe carência de pesquisas que examinem variáveis institucionais (grupo IES) (Miranda et al., 2015). O presente estudo, portanto, tem como objetivo analisar a associação entre variáveis institucionais e o desempenho acadêmico de estudantes da área de negócios (administração e contabilidade). Mais especificamente, este estudo está interessado nas seguintes variáveis relacionadas à IES: organização acadêmica, região geográfica, modalidade de ensino e turno do curso.

Enquanto a análise de variáveis dos grupos CDI e CDO fornecem uma visão mais micro de como o desempenho discente é afetado, a investigação de variáveis do grupo IES permite enxergar a performance acadêmica de uma perspectiva mais macro. Variáveis institucionais dão suporte ao aluno durante o seu processo educacional por representarem a infraestrutura das salas de aula, as instalações da instituição, os materiais e recursos disponibilizados (Miranda et al., 2015). Adicionalmente, as IES podem apresentar localizações e organizações acadêmicas estratégicas para atrair estudantes. Da mesma forma, podem oferecer cursos em diferentes turnos e regiões a fim de pluralizar o acesso ao conhecimento por potenciais alunos. A seu interesse, os discentes, então, podem escolher como desejam estudar com o intuito de conseguir conciliar, satisfatoriamente, a sua vida acadêmica com a vida pessoal e de trabalho. Desta forma, examinar as variáveis institucionais trazem achados de caráter complementar à literatura prévia.

A contribuição deste trabalho repousa em três principais pontos. Primeiro, argumenta-se que a investigação de variáveis institucionais é pertinente porque pode promover mudanças no nível da IES que, por sua vez, podem ajudar, além dos cursos de negócios, os cursos de graduação de forma geral. A compreensão dos fatores institucionais que dão base ao processo educacional dos alunos concorre para, em última instância, elevar a sua performance. $\mathrm{O}$ avanço 
proposto por este artigo é, portanto, um melhor entendimento do desempenho acadêmico de forma mais contextualizada. As variáveis dos grupos CDI e CDO são referentes aos alunos e docentes em suas condições particulares de ensino e aprendizagem. Ao examinar as variáveis do grupo IES, adiciona-se o componente contextual. Segundo, este trabalho provê contribuição metodológica. Diferentemente de estudos sobre o desempenho acadêmico que utilizam modelos de regressão tradicionais (i.e.: lineares via mínimos quadrados ordinários), empregou-se, nesta pesquisa, o modelo de regressão Box Cox Cole Green (BCCG) com zeros ajustados, o qual se mostrou apropriado, como discutido adiante. Estudos futuros podem fazer uso desta técnica de análise quando deparados com conjuntos de dados semelhantes ao deste trabalho, especialmente aqueles relacionados à análise do desempenho discente no Enade, cujo banco de dados serviu de base para este estudo, como discutido na seção metodológica. Terceiro, Miranda et al. (2015) perceberam que "foram poucos os estudos que versavam sobre as instituições de ensino, sobre sua infraestrutura ou sobre sua organização escolar. Além disso, os resultados foram bastante divergentes, não possibilitando estabelecer conclusões sobre os resultados apresentados" (p. 198). Os autores da presente pesquisa enxergam esta quantidade inferior de estudos sobre as variáveis de IES e de achados conflitantes como oportunidade de contribuição ao corpo de evidências obtido até então.

O restante do artigo está organizado da seguinte forma: a seção 2 traz o referencial teórico, no qual se discutem pesquisas e traçam-se raciocínios acerca do desempenho discente e das variáveis institucionais; a seção 3 descreve os procedimentos e decisões metodológicas da pesquisa, focando-se na descrição do banco de dados e técnica de análise; a seção 4 reporta os resultados e estabelece conversa com a literatura prévia; e a seção 5 debate as conclusões, implicações, limitações e sugestões para futuras investigações.

\section{REFERENCIAL TEÓRICO}

\subsection{Performance discente e grupos CDI, CDO e IES}

De acordo com Miranda et al. (2015), as variáveis relacionadas ao desempenho acadêmico de estudantes da área de negócios podem ser classificadas dentro de três grandes grupos: CDI, CDO e IES. No grupo CDI, a preocupação reside em examinar como as variáveis do aluno estão associadas à sua performance. Ahinful et al. (2019), por exemplo, encontraram evidências de que fatores motivacionais (expectativa e volição) e de engajamento e comprometimento (interesse acadêmico e atitude de aprendizagem) influenciavam significativamente o desempenho de discentes de contabilidade. Em outro estudo, Stice, Stice e Albrecht (2020) investigaram como as escolhas de estudo dos estudantes estavam associados ao seu desempenho e constataram que os discentes que liam textos obtiveram melhores performances do que aqueles que assistiam a vídeos como estratégia de aprendizagem. As características evidenciadas por estas pesquisas são referentes aos alunos e, portanto, estão categorizadas no CDI.

No grupo CDO, as pesquisas têm como foco a relação entre as variáveis dos professores e o desempenho dos estudantes. Westerman, Whitaker, Bergman, Bergman e Daly (2016) analisaram o narcisismo de docentes e alunos da área de negócios e verificaram que o narcisismo está significantemente associado à nota final dos estudantes. Em particular, encontrou-se que professores narcisistas estão relacionados a notas menores obtidas por alunos menos narcisistas. No CDO também estão incluídas as estratégias de ensino utilizadas pelos professores. A esse respeito, pesquisas têm testado múltiplas técnicas pedagógicas visando aumentar a performance discente, tais como jogos e gamificação (Beatson et al., 2020; ElKelish \& Ahmed, 2021; Kuang, Adler, \& Pandey, 2021), tecnologia (Francescucci, Kellershohn, \& Pyle, 2021; Namin, Ketron, Kaltcheva, \& Winsor, 2021), estudo de caso instrucional (Cheng, Sapkota, \& Yurko, 2021), 
narrativas (Grimm, 2021; Taylor, Marrone, Tayar, \& Mueller, 2017), tipo, frequência e políticas de avaliação (Miglietti, 2021; Nakos \& Whiting, 2018; Nsor-Ambala, 2020) e assim por diante. No caso do grupo IES, o propósito é verificar como variáveis das instituições de ensino estão associadas ao desempenho acadêmico. Neste grupo, Miranda et al. (2015) incluem os recursos tecnológicos, a infraestrutura da sala de aula, os recursos didáticos e as instalações, por exemplo. Kafaji (2020) objetivou analisar os benefícios percebidos pelos estudantes acerca do credenciamento (accreditation) das escolas de negócios privadas e a sua relação com o desempenho, a motivação e a prospecção de carreira dos estudantes. Por meio de modelagem de equações estruturais, encontrou-se que o credenciamento tem associação positiva com o desempenho discente.

Em comparação com o CDI e o CDO, o grupo IES apresenta menor ocorrência de estudos (Miranda et al., 2015). Potencialmente, isto acontece porque existe uma visualização mais direta das relações entre o desempenho acadêmico e as variáveis dos estudantes e dos professores. Quando se trata da instituição, esta percepção é menos imediata. Nem por isso, esforços devem deixar de ser feitos. Pelo contrário, a menor ocorrência de pesquisas denota que há espaço para contribuições relevantes à literatura do desempenho acadêmico na área de negócios advindas de análises de variáveis institucionais. Isto pode fornecer subsídios para melhor guiar a escolha do tipo da IES e do curso por futuros ingressantes. O desempenho acadêmico deve ser, portanto, observado e monitorado a partir das três óticas, como ilustrado na Figura 1.

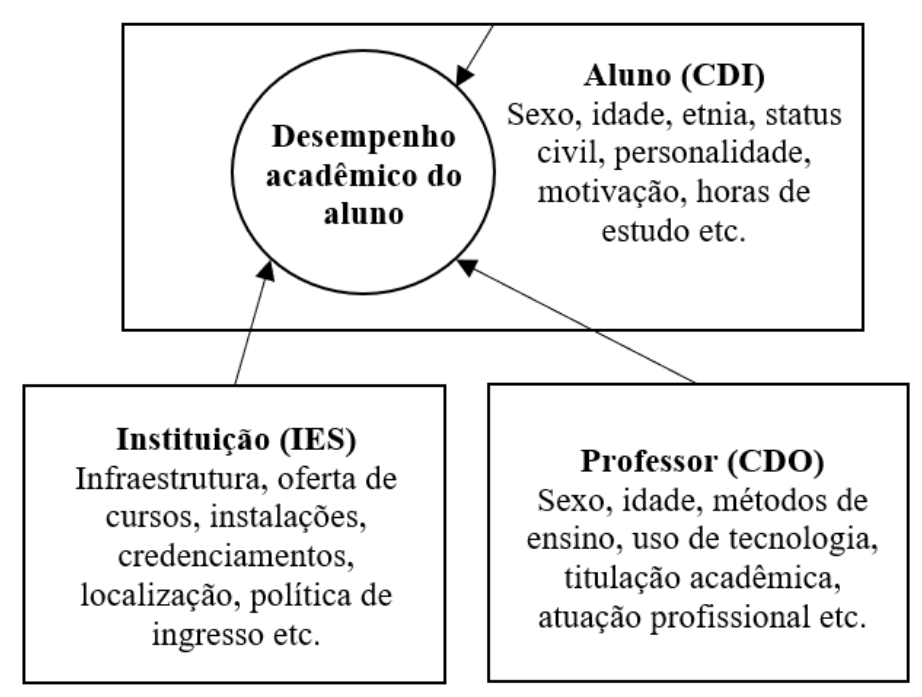

Figura 1. Determinantes do desempenho acadêmico

Fonte: Elaborado pelos autores com base em Miranda et al. (2015).

Investigações futuras sobre a performance acadêmica podem incluir, em adição às variáveis dos grupos CDI e CDO, as do grupo IES em seus modelos de análise para obter achados mais completos. Nesta pesquisa, focalizam-se somente as variáveis institucionais. Particularmente, examina-se a relação entre o desempenho do estudante e a organização acadêmica, a região, a modalidade de ensino e o turno do curso.

\subsection{Variáveis institucionais}

De acordo com Fogarty, Zimmerman e Richardson (2016), as IES exercem dois papéis sociais centrais. O primeiro é o de educar a sociedade e o segundo é o de produzir novos conhecimentos. No papel de educação da população, as IES atingem este objetivo ao preparar os seus estudantes para a atividade profissional escolhida. No caso da ampliação do conhecimento, 
as IES usualmente atingem este fim ao desenvolver pesquisas. Embora o desempenho acadêmico possa estar mais diretamente relacionado à primeira atuação social, há propostas relevantes de integração da pesquisa ao ensino como forma de aperfeiçoar a aprendizagem do estudante (Madsen, 2020). Deste modo, a forma como as IES estão organizadas e oferecem cursos pode influenciar o desempenho dos seus estudantes.

As variáveis institucionais são características que estão mais associadas à IES, em vez de discentes e docentes. Nesta pesquisa, dá-se ênfase à organização acadêmica, à regionalidade, à modalidade de ensino e ao turno. A começar pela organização acadêmica, Baldo (2018) discute as formas de organização que as IES podem assumir. Primeiro, a autora evidencia as universidades, caracterizadas pela sua atuação pluridisciplinar e pela indissociabilidade do ensino, da pesquisa e da extensão, além da autonomia didático-científica. No caso dos centros universitários, a atividade de pesquisa não é obrigatória (Baldo, 2018), mas existe autonomia similar à das universidades. As faculdades, por sua vez, são IES que oferecem um ou mais cursos superiores, mas não possuem autonomia e, por esta razão, devem solicitar, ao Ministério da Educação, autorização para abertura ou fechamento de cursos, aumento ou redução do número de vagas, dentre outros processos. Os institutos superiores de educação (ISE) são aqueles que "visam a formação inicial, continuada e complementar para o magistério da educação básica" (Baldo, 2018, p. 12). Por fim, há os centros de educação tecnológica e centros federais de educação tecnológica (Cefets) que atuam na educação profissional pós-secundária com o propósito de qualificação profissional nos múltiplos níveis educacionais e por meio de distintas modalidades de ensino, servindo como mecanismo de educação continuada (Baldo, 2018).

O trabalho de Bervian e Corrêa (2015) analisou o desempenho de alunos de administração de universidades, centros universitários e faculdades e não encontrou diferença relevante. Já no trabalho de Caetano et al. (2015), estudantes de universidades obtiveram melhores performances do que alunos oriundos de outros tipos de IES. Santos (2012) investigou os determinantes do desempenho acadêmico de alunos de ciências contábeis, incluindo a organização acadêmica da IES. Esta variável foi mensurada da seguinte forma: 1 para universidades e centros universitários e 0 para faculdades integradas, faculdades, escolas e institutos superiores, centros de educação e tecnológicos. Os resultados mostraram que, para o Provão 2002, a organização acadêmica não foi significante. Entretanto, foi significativa no Provão 2003 e no Enade 2006, nos quais alunos de universidades e centros universitários obtiveram melhores performances. Considerando as distintas características assumidas em cada tipo de organização acadêmica e os achados empíricos descritos, a primeira hipótese desta pesquisa é formulada da seguinte forma:

H1: Há diferença significante entre o desempenho de alunos matriculados em diferentes formas de organização acadêmica.

A região da IES e/ou do curso de graduação tem sido alvo mais frequente de pesquisas acadêmicas que envolvam o desempenho discente e são essenciais por poderem evidenciar discrepâncias significativas no desempenho dos alunos regionalmente (ver, por exemplo, Brandt, Tejedo-Romero \& Araujo, 2020; Mallman et al., 2021; Nasu \& Sasso, 2021; Santos, 2012). Desta forma, possibilita-se verificar se alguma região possui um ensino mais deficitário em relação às demais e como isto pode ser ajustado. As análises de Nasu e Sasso (2021) apontaram que a performance de alunos de cursos da área de negócios da região Norte era materialmente maior do que os da região Sul, inferior aos das regiões Nordeste e Sudeste e semelhante aos da região Centro-Oeste. No caso do estudo de Mallmann et al. (2021), no qual foi examinado o desempenho de alunos da área de ciências sociais aplicadas, constatou-se que os discentes da região Sudeste tiveram performances significativamente maiores em relação aos das demais 
regiões. Similarmente, utilizando-se de dados de estudantes de administração pública, Brandt et al. (2020) apuraram que aqueles vinculados à região Sudeste sobressaíram comparativamente aos das demais regiões. No estudo de Santos (2012) foi encontrado que os alunos das regiões Sul e Sudeste (categorizados como 1) obtiveram performance superior aos das ouras regiões (categorizados como 0). Estas evidências sugerem que a região na qual se encontra a IES/curso pode ter efeito relevante sobre o desempenho dos estudantes. Santos, Pales e Rodrigues (2014) destacam as desigualdades das regiões brasileiras com base em dados socioeconômicos históricos (1991-2010), constatando que as regiões Norte e Nordeste são as mais desfavorecidas. Dados da Pesquisa Nacional por Amostra de Domicílios Contínua (PNAD Contínua) - Educação 2019, elaborada pelo Instituto Brasileiro de Geografia e Estatística (IBGE, 2019), também mostram que as regiões Norte e Nordeste apresentam as situações mais desfavoráveis educacionalmente. Com base neste cenário histórico, a segunda hipótese é apresentada a seguir:

H2: As regiões Norte e Nordeste estão negativamente associadas ao desempenho acadêmico.

A influência da modalidade de ensino sobre o desempenho discente vem chamando atenção de pesquisadores, em particular nas últimas duas décadas, nas quais houve aceleração do avanço tecnológico que viabilizou novas formas de gerar e disseminar conteúdo, dando surgimento, também, a novas modalidades de ensino formal (ver, por exemplo, Caetano et al., 2015; Fortin, Viger, Deslandes, Callimaci \& Desforges, 2019; McCarthy, Kusaila \& Grasso, 2019; Rodrigues et al. 2016; Nasu 2020; Santos, 2012). Neste contexto, Rodrigues et al. (2016) investigaram os determinantes do desempenho acadêmico de alunos de ciências contábeis do ensino a distância (EaD) e acharam que as variáveis do grupo CDI eram as mais influentes. Similarmente, Nasu (2020) averiguou que os fatores sociodemográficos dos estudantes também se apresentaram relevantes. Em estudo conduzido com alunos das disciplinas de contabilidade intermediária III e Auditoria, McCarthy et al. (2019) encontraram evidências de que o desempenho acadêmico foi similar quando consideradas as modalidades presencial, híbrida e online. Ainda, Fortin et al. (2019) procuraram examinar o formato da modalidade de ensino híbrido e a sua relação com o desempenho e a satisfação discentes. Especificamente, analisaramse duas modalidades híbridas: F2F+ (curso com aulas predominantemente presenciais) e Online+ (curso com aulas predominantemente online). Como resultados, percebeu-se que os alunos desempenharam de forma semelhante nos dois formatos de ensino híbrido. Os achados de Caetano et al. (2015) mostram que os alunos do ensino presencial obtiveram melhores notas em comparação aos do EaD. Da mesma forma, o seu nível de satisfação foi similar. Estes resultados suportam que a modalidade de ensino pode estar significativamente conectada à performance acadêmica. A rápida expansão do ensino superior por meio do $\mathrm{EaD}$ tem levantado questionamento acerca da sua qualidade (Alonso, 2010; Bertolin, 2021). Bertolin (2021), por exemplo, nota que há distinção de qualidade entre o ensino presencial e a distância, sendo o primeiro de qualidade mais elevada. $\mathrm{Na}$ área de ciências contábeis, evidências sugerem que empregadores (empresas) preferem contratar funcionários que estudaram na modalidade presencial (Grossman \& Johnson, 2016), mesmo quando eles mesmos tenham concluído o curso de graduação no formato a distância (Grossman \& Johnson, 2017). Desta forma, a terceira hipótese é formulada como segue:

H3: A modalidade de ensino presencial está positivamente associada ao desempenho acadêmico.

A última variável institucional investigada por esta pesquisa é o turno do curso. Este aspecto, à primeira vista, pode não parecer estar associado ao desempenho discente, mas é reflexo de importantes condições de aprendizagem. Por exemplo, Andreoli e De Martino (2012) 
angariaram evidências de que os padrões de estudantes universitários do turno matutino eram relevantemente distintos dos do turno da noite e que o desempenho daqueles eram superiores ao destes. Os achados da pesquisa de Farias, Alves e Farias (2015) também sustentam que estudantes do turno diurno (manhã e tarde) têm performances significativamente melhores do que os do noturno. Na pesquisa de Mallmann et al. (2021) constatou-se que estudantes do turno integral performaram melhor do que os dos turnos matutino, vespertino e noturno. Este achado é consistente com a expectativa, já que este tipo de turno requer que os alunos se dediquem aos estudos em tempo integral. Por sua vez, Moura, Miranda e Pereira (2015) encontraram que alunos de ciências contábeis da Universidade Federal de Uberlândia (UFU) do turno da noite obtiveram melhores desempenhos em comparação aos do turno integral. Consistentemente, os docentes da UFU afirmaram que os estudantes da noite tendem a ter desempenho maiores em relação aos do integral. Este resultado pode estar relacionado a características particulares do contexto investigado, já que é um achado contraintuitivo. Ainda, há evidências de que o desempenho não está associado significantemente ao turno (Cornachione Junior et al., 2010). Embora os achados empíricos apresentem certo grau de conflito, parece razoável esperar que os alunos que estudam em turno integral obtenham melhores performances. Como observado por Cornachione Junior et al. (2010), é típico que os estudantes da área de negócios do turno noturno trabalhem durante o dia e cursem a graduação a noite. Desta forma, há menor quantidade de horas de estudo disponível em comparação, por exemplo, com os estudantes do turno integral ou, até mesmo, dos turnos matutino ou vespertino. Portanto, a quarta hipótese da pesquisa é reportada da seguinte maneira:

H4: O turno integral está positivamente associado ao desempenho acadêmico.

Ressalta-se que outras variáveis institucionais existem e a sua inserção nos modelos de análise de pesquisas futuras é encorajada. Entretanto, considerando a sua menor aparição, principalmente em relação a variáveis dos grupos CDI e CDO, este trabalho vem fortificar a literatura a partir do foco na organização acadêmica, região, modalidade de ensino e turno. Gradualmente, outras variáveis podem ser consideradas.

\section{METODOLOGIA}

O presente estudo fez uso dos microdados do Exame Nacional de Desempenho de Estudantes (Enade) 2018, os quais foram coletados do website do Instituto Nacional de Estudos e Pesquisas Educacionais Anísio Teixeira (INEP, 2021). Salienta-se que o Enade 2018 foi a última edição realizada pelos estudantes de administração e contabilidade cujos dados estão disponíveis. É pertinente indicar que a nota final do aluno do Enade é composta por $25 \%$ do seu desempenho na prova de formação geral (questões que envolvem temáticas gerais, tais como responsabilidade social e globalização) e $75 \%$ na prova de componente específico (questões específicas de cada curso). Neste estudo, foram levadas em conta as três formas de mensuração do desempenho do aluno.

Posteriormente à coleta, foram selecionadas, dentre todas as disponibilizadas pelo Enade, as variáveis de interesse deste estudo, conforme especifica a Tabela 1 . O desempenho acadêmico foi mensurado de três formas: desempenho final (DEF), desempenho na prova de formação geral (DFG) e desempenho na prova de componente específico (DCE). No caso das variáveis institucionais, foram consideradas a organização acadêmica (OAC), a região geográfica (REG), a modalidade de ensino (MOD) e o turno do curso (TUR). Uma vez selecionadas tais variáveis, observou-se a presença de missing values e de NAs. Estes casos foram excluídos, permanecendo, ao todo, 152.491 observações $(83,38 \%$ do total). 
Tabela 1

Variáveis da pesquisa

\begin{tabular}{|c|c|c|}
\hline Sigla & Descrição & Mensuração \\
\hline DEF & Desempenho final & 0 a 100 pontos. \\
\hline DFG & $\begin{array}{l}\text { Desempenho na prova de } \\
\text { formação geral }\end{array}$ & 0 a 100 pontos. \\
\hline DCE & $\begin{array}{l}\text { Desempenho na prova de } \\
\text { componente específico }\end{array}$ & 0 a 100 pontos. \\
\hline OAC & Organização acadêmica da IES & $\begin{array}{l}\text { Universidade; Faculdade; Centro Universitário (CUniv); } \\
\text { Instituto Federal de Educação, Ciência e Tecnologia (IF); Centro } \\
\text { Federal de Educação Tecnológica (Cefet). }\end{array}$ \\
\hline REG & Região geográfica & Norte; Nordeste; Centro-oeste; Sudeste; Sul. \\
\hline MOD & Modalidade de ensino & Presencial; A distância (EaD). \\
\hline TUR & Turno & Matutino; Vespertino; Noturno; Integral. \\
\hline
\end{tabular}

Procedeu-se, então, à etapa de seleção da técnica de análise. A princípio, efetuou-se a análise exploratória dos dados, focando-se nas estatísticas descritivas e histogramas. A Tabela 2 mostra a média, mediana, desvio-padrão, mínimo e máximo das variáveis de desempenho. Ao observar as médias, percebe-se que a performance foi relativamente baixa, dado que o intervalo das notas era de 0 a 100 pontos. A média do DEF foi de 37,88 pontos, indicando que, de modo geral, os estudantes performaram abaixo da metade (50 pontos) da nota possível. Avaliando-se o desempenho por tipo de prova, nota-se que os estudantes obtiveram melhor desempenho na prova de formação geral (média $=42,80$ ) comparativamente à performance na prova de conhecimento específico (média $=36,22$ ). Este achado torna evidente a importância do reforço do conhecimento específico do aluno em relação à profissão escolhida. Neste caso, a de contador ou administrador. Os valores mínimos também representam indícios de que o conhecimento dos estudantes pode ser aprimorado, já que houve pelo menos uma observação que obteve nota zero.

Tabela 2

\section{Estatísticas descritivas do desempenho dos estudantes}

\begin{tabular}{cccccc}
\hline Variáveis quantitativas & Média & Mediana & Desvio-padrão & Mínimo & Máximo \\
\hline DEF & 37,88 & 37,1 & 12,96 & 0 & 92,8 \\
DFG & 42,80 & 42,3 & 16,59 & 0 & 96,4 \\
DCE & 36,22 & 35,6 & 14,06 & 0 & 95,2 \\
\hline
\end{tabular}

A Tabela 3 mostra as frequências absoluta e relativa das variáveis relacionadas à IES. Destaca-se que a maior parte dos estudantes que fez o Enade 2018 estava matriculada em universidades $(48,80 \%)$, era da região Sudeste $(43,49 \%)$, estudava na modalidade presencial $(76,00 \%)$ e era do turno noturno $(82,39 \%)$. Por outro lado, o Cefet $(0,10 \%)$, a região Norte $(4,74 \%)$, o $\mathrm{EaD}(24 \%)$ e o turno vespertino $(1,22 \%)$ são as categorias que apresentaram a menor frequência. Esta descrição é compatível com o esperado, visto que o típico aluno de negócios tende a ser do curso do período noturno (principalmente por motivo de trabalho), da região Sudeste (maior população) e do ensino presencial de universidades (maior quantidade de vagas). Estas características foram percebidas por pesquisa prévia (Cornachione Junior et al., 2010). 
Tabela 3

Frequências das variáveis institucionais

\begin{tabular}{lcc}
\hline Variáveis qualitativas & Frequência absoluta & Frequência relativa \\
\hline OAC - Cefet & 148 & 0,10 \\
OAC - CUniv & 33.586 & 22,02 \\
OAC - Faculdade & 43.442 & 28,48 \\
OAC - IF & 897 & 0,58 \\
OAC - Universidade & 74.418 & 48,80 \\
REG - Norte & 7.220 & 4,74 \\
REG - Nordeste & 25.457 & 16,69 \\
REG - Sudeste & 66.326 & 43,49 \\
REG - Sul & 42.163 & 27,64 \\
REG - Centro-Oeste & 11.325 & 7,42 \\
MOD - Presencial & 115.904 & 76,00 \\
MOD - EaD & 36.587 & 24,00 \\
TUR - Matutino & 13.116 & 8,60 \\
TUR - Vespertino & 1.870 & 1,22 \\
TUR - Integral & 11.854 & 7,77 \\
TUR - Noturno & 125.651 & 82,39 \\
\hline
\end{tabular}

Na sequência, os histogramas das variáveis de desempenho estão reportados na Figura 2. Os histogramas da esquerda, do centro e da direita são, respectivamente, referentes às variáveis DEF, DFG e DCE. Percebe-se que nas três notas há ocorrência de zeros, representada pela linha vertical com o ponto vermelho no topo e as distribuições são aproximadamente simétricas. Esta simetria indica que um modelo Normal talvez seja adequado na modelagem das notas. Contudo, ao realizar os testes de Shapiro-Wilk, constatou-se que as notas não são normalmente distribuídas $(\mathrm{p}<0,05)$. Por este motivo, foi verificado que os modelos de regressão convencionais (i.e.: lineares via mínimos quadrados ordinários) não se apresentaram adequados ao presente conjunto de dados.
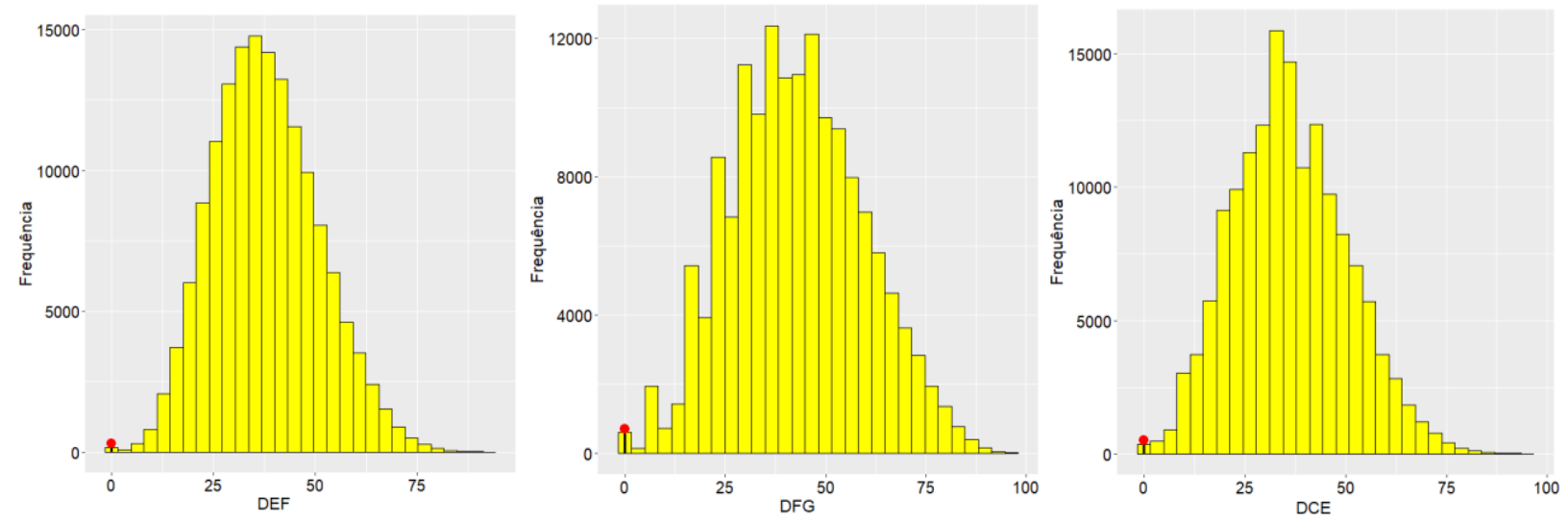

Figura 2. Histogramas das variáveis de desempenho do aluno (DEF, DFG e DCE) Fonte: Dados da pesquisa.

Diante destes resultados, foi necessário recorrer a outro tipo de modelagem que acomodasse tanto o excesso de zeros quanto a simetria da distribuição das notas positivas. Uma alternativa é a utilização de modelos de mistura (Stasinopoulos, Enea, \& Rigby, 2017), os quais apresentam uma função densidade de mistura discreta-contínua da forma especificada na Equação (1): 


$$
f_{y}(y \mid \boldsymbol{\theta}, \xi)=\left\{\begin{array}{l}
\xi, \text { se } y=0 \\
(1-\xi) f_{W}(y \mid \boldsymbol{\theta}), \text { se } 0<y<\infty
\end{array}\right.
$$

em que $0 \leq y<\infty$ representa o suporte da variável resposta (DEF, DFG e DCE); $f_{W}(y \mid \boldsymbol{\theta})$ representa alguma função densidade de probabilidade contínua definida no intervalo $(0, \infty)$ com parâmetros $\boldsymbol{\theta}^{T}=\left(\theta_{1}, \theta_{2}, \ldots, \theta_{p}\right)$; e, por fim, $0<\xi<1$, onde $\xi=P(Y=0)$, é a probabilidade de ocorrência da nota zero (Stasinopoulos et al., 2017). Deste modo, para a parte referente aos zeros, emprega-se a modelagem binomial e, para a parte contínua é necessário encontrar uma distribuição que se ajuste de modo adequado à continuidade dos dados.

Uma das formas para encontrar tal distribuição é por meio do uso dos Modelos Aditivos Generalizados para Locação, Escala e Forma (GAMLSS). Utilizou-se a função ChooseDist () do pacote gamlss (Stasinopoulos et al., 2021) para se obter as distribuições candidatas à modelagem da parte contínua das variáveis dependentes (DEF, DFG e DCE). Para efetuar a escolha da distribuição mais apropriada, levou-se em consideração o Critério de Informação de Akaike Generalizado (GAIC). Para as três variáveis dependentes, a distribuição que mais se adequou à parte contínua dos dados foi a BCCG.

Diante disso, $Y \sim \operatorname{ZABCCG}(\mu, \sigma, v, \xi)$ se refere à uma distribuição BCCG Zero Ajustada de parâmetros $0<\mu<\infty, 0<\sigma<\infty,-\infty<v<\infty$ e $0<\xi<1$, em que $0 \leq y<\infty$ e $W \sim \operatorname{BCCG}(\mu, \sigma, v)$. $W$, portanto, segue uma distribuição BCCG de parâmetros $(\mu, \sigma, v)$ (Rigby, Stasinopoulos, Heller, \& De Bastiani, 2019). A função de ligação utilizada para $\mu$ e $v$ é a identidade, para $\sigma$ é a log e para $\xi$ é a logito. Salienta-se que, dependendo da qualidade do ajuste, outras funções de ligação podem ser empregadas. Neste trabalho, contudo, isto não foi necessário visto que a qualidade do ajuste foi satisfatória. A Equação (2) reporta a função densidade de probabilidade $f_{W}(y)$ quando $v \neq 0$ :

$$
f_{w}(y \mid \mu, \sigma, v)=\frac{y^{v-1} \exp \left(-\frac{1}{2} z^{2}\right)}{\mu^{v} \sigma \sqrt{2} \pi \Phi\left[(\sigma \mid v)^{-1}\right]^{\prime}}
$$

em que $\Phi(.)^{-1}$ denota a inversa da função de distribuição acumulada da distribuição Normalpadrão e z é uma constante definida por $-\frac{1}{\sigma \nu}<z<\infty$ para $v \neq 0$ ou $-\infty<z<-\frac{1}{\sigma \nu}$ para $v<0$. Uma vez definidas as distribuições para a modelagem dos dados e as funções de ligação de cada parâmetro, formulou-se o modelo de regressão BCCG com zeros ajustados (Equações (3), (4) e (5)), incluindo a estimação de $\xi_{0}$ (Equação (6)), que é o resultado exponencial de $\xi$, conforme discriminado anteriormente. Frisa-se que este modelo foi utilizado para a estimação das três formas de mensuração do desempenho do estudante (DEF, DFG e DCE):

$$
\begin{aligned}
\mu_{i} & =\beta_{0}+\beta_{1} \text { CUniv }+\beta_{2} \text { Faculdade }+\beta_{3} I F+\beta_{4} \text { Universidade }+\beta_{5} \text { Nordeste }+ \\
& +\beta_{6} \text { Sudeste }+\beta_{7} \text { Sul }+\beta_{8} \text { Centro }- \text { oeste }+\beta_{9} \text { EaD }+\beta_{10} \text { Vespertino }+ \\
& +\beta_{11} \text { Integral }+\beta_{12} \text { Noturno }
\end{aligned}
$$

$$
\begin{aligned}
\log \left(\sigma_{i}\right) & =\beta_{0}+\beta_{1} \text { CUniv }+\beta_{2} \text { Faculdade }+\beta_{3} \text { IF }+\beta_{4} \text { Universidade }+\beta_{5} \text { Nordeste }+ \\
& +\beta_{6} \text { Sudeste }+\beta_{7} \text { Sul }+\beta_{8} \text { Centro }- \text { oeste }+\beta_{9} \text { EaD }+\beta_{10} \text { Vespertino }+ \\
& +\beta_{11} \text { Integral }+\beta_{12} \text { Noturno }
\end{aligned}
$$

$$
\begin{aligned}
v_{i} & =\beta_{0}+\beta_{1} \text { CUniv }+\beta_{2} \text { Faculdade }+\beta_{3} I F+\beta_{4} \text { Universidade }+\beta_{5} \text { Nordeste }+ \\
& +\beta_{6} \text { Sudeste }+\beta_{7} \text { Sul }+\beta_{8} \text { Centro }- \text { oeste }+\beta_{9} \text { EaD }+\beta_{10} \text { Vespertino }+ \\
& +\beta_{11} \text { Integral }+\beta_{12} \text { Noturno }
\end{aligned}
$$


$\xi_{0}=\frac{\exp (\xi)}{1+\exp (\xi)}$

É oportuno apontar, ainda, que as categorias de referência (baseline) das variáveis OAC, REG, MOD e TUR são, respectivamente, as seguintes: Cefet, Norte, Presencial e Matutino. Para avaliar a qualidade dos ajustes dos três modelos de regressão BCCG com zeros ajustados, foram examinados os resíduos quantílicos aleatorizados (Dunn \& Smyth, 1996). Por meio do gráfico de resíduos vs. preditos constatou-se que o modelo é adequado aos dados, uma vez que os resíduos estão distribuídos de forma homogênea em torno do zero. Além disso, o gráfico quantil-quantil (qqplot) mostrou não haver grandes desvios da distribuição dos resíduos em relação à distribuição Normal, indicando adequado ajuste da distribuição BCCG e do modelo aos dados. Para maiores detalhes, consultar o Apêndice A. O nível de significância adotado foi de 5\% e as análises foram realizadas no software R versão 4.0.2 (R Core Team, 2020) e SAS versão 9.4 (SAS Institute, 1996).

\section{RESULTADOS}

\subsection{Resultados dos modelos de regressão}

A Tabela 4 reporta o resultado do modelo de regressão BCCG com zeros ajustados para o parâmetro $\left(\mu_{\mathbf{i}}\right)$ cuja variável dependente é a DEF. Nota-se que, com exceção do parâmetro associado à categoria TUR - Vespertino, os demais se mostraram significantes $(\mathrm{p}<0,05)$. No caso da variável OAC, constata-se que, comparativamente à nota de estudantes de Cefets, em média, as notas de alunos de centros universitários, faculdades, institutos federais e universidades são relevantemente menores em 13,38, 15,92, 10,55 e 12,54 pontos, respectivamente.

Tabela 4

\section{Resultado do modelo BCCG com zeros ajustados (parâmetro $\left(\mu_{i}\right)$ para o DEF}

\begin{tabular}{|c|c|c|c|c|}
\hline DEF & Estimativa & Erro-padrão & Estatística $t$ & Valor-p \\
\hline (Intercepto) & 53,18 & 1,30 & 40,87 & $<0,0001$ \\
\hline OAC-CUniv & $-13,38$ & 1,28 & $-10,38$ & $<0,0001$ \\
\hline OAC - Faculdade & $-15,92$ & 1,28 & $-12,36$ & $<0,0001$ \\
\hline $\mathrm{OAC}-\mathrm{IF}$ & $-10,55$ & 1,37 & $-7,67$ & $<0,0001$ \\
\hline OAC - Universidade & $-12,54$ & 1,28 & $-9,74$ & $<0,0001$ \\
\hline REG - Nordeste & 0,88 & 0,17 & 5,15 & $<0,0001$ \\
\hline REG - Sudeste & 2,33 & 0,16 & 14,61 & $<0,0001$ \\
\hline REG - Sul & 2,42 & 0,16 & 14,31 & $<0,0001$ \\
\hline REG - Centro-Oeste & 0,69 & 0,19 & 3,57 & $<0,0001$ \\
\hline $\mathrm{MOD}-\mathrm{EaD}$ & $-6,36$ & 0,09 & $-67,32$ & $<0,0001$ \\
\hline TUR - Vespertino & $-0,20$ & 0,36 & $-0,58$ & 0,56 \\
\hline TUR - Integral & 2,96 & 0,19 & 15,47 & $<0,0001$ \\
\hline TUR - Noturno & $-2,68$ & 0,13 & $-20,08$ & $<0,0001$ \\
\hline$\xi_{0}=\boldsymbol{P}(\boldsymbol{Y}=\mathbf{0})$ & $-6,97$ & 0,08 & $-83,11$ & $<0,0001$ \\
\hline
\end{tabular}

Nota. Para a tabela da estimação dos parâmetros de escala $\left(\log \left(\sigma_{i}\right)\right)$ e forma $\left(\left(v_{i}\right)\right)$, favor consultar o Apêndice B.

Para a região, verifica-se que as notas dos estudantes da região Norte (baseline) foram, em média, significativamente inferior às notas de alunos das regiões Nordeste, Sudeste, Sul e Centro-oeste em $0,88,2,33,2,42$ e 0,69 pontos, respectivamente. No que tange à modalidade, 
observa-se que os estudantes do EaD obtiveram piores notas do que os do presencial. Especificamente, a nota daqueles foi, em média, inferior à nota destes em 6,36 pontos. Por fim, alunos cujo turno do curso é integral obtiveram, em média, 2,96 pontos a mais do que os estudantes do turno matutino. Por outro lado, alunos do curso noturno tiraram 2,68 pontos a menos no Enade do que os do matutino. E não houve diferença significante entre os desempenhos dos estudantes dos turnos matutino e vespertino $(p>0,05)$.

$\mathrm{Na}$ Tabela 5 está retratado o resultado do modelo BCCG com zeros ajustados relativo ao parâmetro $\left(\mu_{\mathbf{i}}\right)$ cuja variável dependente é a DFG. Com exceção dos parâmetros das categorias OAC - IF e REG - Nordeste, REG - Sudeste e TUR - Vespertino, o restante apresentou significância $(p<0,05)$. Para a variável OAC, averigua-se que a nota de estudantes de centros universitários, faculdades e universidades é inferior a de alunos de Cefets, dado que as estimativas são negativas. Mais especificamente, os alunos de Cefets (categoria de referência) obtiveram, em média, 13,56, 16,05, 10,23 e 11,54 pontos a mais do que estudantes matriculados em centros universitários, faculdades, IFs e universidades, respectivamente. De caráter suplementar à literatura prévia, este achado derivado da comparação entre as múltiplas formas de estruturação acadêmica enfatiza a sua relevância para fins de performance discente. Estudos futuros podem expandir esta linha de análise tendo em mente este resultado significante.

Tabela 5

Resultado do modelo BCCG com zeros ajustados (parâmetro $\left(\mu_{i}\right)$ para o DFG

\begin{tabular}{lcccc}
\hline DFG & Estimativa & Erro-padrão & Estatística $\boldsymbol{t}$ & Valor-p \\
\hline (Intercepto) & 59,93 & 4,28 & 14,00 & $<0,0001$ \\
OAC - CUniv & $-13,56$ & 4,27 & $-3,17$ & $<0,0001$ \\
OAC - Faculdade & $-16,05$ & 4,27 & $-3,76$ & $<0,0001$ \\
OAC - IF & $-10,23$ & 4,31 & $-2,37$ & 0,02 \\
OAC - Universidade & $-11,54$ & 4,27 & $-2,70$ & $<0,0001$ \\
REG - Nordeste & 0,19 & 0,23 & 0,82 & 0,41 \\
REG - Sudeste & 0,54 & 0,22 & 2,45 & 0,01 \\
REG - Sul & 0,99 & 0,23 & 4,27 & $<0,0001$ \\
REG - Centro-Oeste & $-1,08$ & 0,27 & $-4,03$ & $<0,0001$ \\
MOD - EaD & $-5,28$ & 0,12 & $-42,30$ & $<0,0001$ \\
TUR - Vespertino & 0,36 & 0,47 & 0,77 & 0,44 \\
TUR - Integral & 3,11 & 0,25 & 12,64 & $<0,0001$ \\
TUR - Noturno & $-3,59$ & 0,17 & $-20,67$ & $<0,0001$ \\
\hline$\xi_{0}=\boldsymbol{P}(\boldsymbol{Y}=\mathbf{0})$ & $-5,57$ & 0,04 & $-133,80$ & $<0,0001$ \\
\hline
\end{tabular}

Nota. Para a tabela da estimação dos parâmetros de escala $\left(\log \left(\sigma_{i}\right)\right)$ e forma $\left(\left(v_{i}\right)\right)$, favor consultar o Apêndice B.

Em relação à região, apura-se que estudantes da região Sudeste e Sul obtiveram, em média, 0,54 e 0,99 ponto a mais do que os da região Norte nas questões de formação geral. Os estudantes da região Nordeste obtiveram desempenho similar aos da região Norte $(\mathrm{p}>0,05)$. Além disso, alunos da região Centro-Oeste tiraram, em média, 1,08 ponto a menos do que os da região Norte. Mesmo que, de forma geral, os alunos da região Centro-Oeste tenham obtido um melhor desempenho final (rever Tabela 4), eles foram superados pelos estudantes da região Norte nas questões de formação geral (DFG). Esta análise permite observar que os alunos da região Centro-Oeste podem, portanto, aprimorar o seu conhecimento de formação geral a fim de alcançar os desempenhos dos estudantes das outras regiões.

Quanto à modalidade de ensino, os estudantes do $\mathrm{EaD}$ tiraram 5,28 pontos a menos do que os do presencial, semelhantemente à análise do DEF. E para o turno, foi constatado que os estudantes do turno integral obtiveram, em média, 3,11 pontos a mais do que os do turno matutino. Em contrapartida, estudantes do turno noturno performaram 3,59 pontos a menos na 
prova de formação geral do Enade em comparação com os do turno matutino. Não houve diferença estatisticamente relevante entre o desempenho de alunos dos turnos matutino e vespertino $(\mathrm{p}>0,05)$.

A Tabela 6 mostra o resultado do modelo BCCG com zeros ajustados referente ao parâmetro $\left(\mu_{\mathbf{i}}\right)$ cuja variável dependente é a DCE. Exceto pelos parâmetros associados à categoria TUR - Vespertino, os outros apresentaram significância $(\mathrm{p}<0,05)$. Na prova de componente específico, estudantes de centros universitários, faculdades, institutos federais e universidades obtiveram notas médias menores do que os de Cefets em 12,27, 14,87, 9,54 e 11,74 pontos, respectivamente.

Tabela 6

Resultado do modelo BCCG com zeros ajustados (parâmetro $\left(\mu_{i}\right)$ para o DCE

\begin{tabular}{|c|c|c|c|c|}
\hline DCE & Estimativa & Erro-padrão & Estatística $t$ & Valor-p \\
\hline (Intercepto) & 50,04 & 1,41 & 35,59 & $<0,0001$ \\
\hline OAC - CUniv & $-12,27$ & 1,39 & $-8,82$ & $<0,0001$ \\
\hline OAC - Faculdade & $-14,87$ & 1,39 & $-10,69$ & $<0,0001$ \\
\hline $\mathrm{OAC}-\mathrm{IF}$ & $-9,54$ & 1,48 & $-6,45$ & $<0,0001$ \\
\hline OAC - Universidade & $-11,74$ & 1,39 & $-8,45$ & $<0,0001$ \\
\hline REG - Nordeste & 1,20 & 0,19 & 6,35 & $<0,0001$ \\
\hline REG - Sudeste & 2,95 & 0,18 & 16,60 & $<0,0001$ \\
\hline REG - Sul & 2,90 & 0,19 & 15,48 & $<0,0001$ \\
\hline REG - Centro-Oeste & 1,38 & 0,22 & 6,39 & $<0,0001$ \\
\hline $\mathrm{MOD}-\mathrm{EaD}$ & $-6,80$ & 0,10 & $-65,65$ & $<0,0001$ \\
\hline TUR - Vespertino & $-0,37$ & 0,40 & $-0,94$ & 0,35 \\
\hline TUR - Integral & 2,92 & 0,21 & 14,09 & $<0,0001$ \\
\hline TUR - Noturno & $-2,46$ & 0,15 & $-16,95$ & $<0,0001$ \\
\hline$\xi_{0}=\boldsymbol{P}(\boldsymbol{Y}=\mathbf{0})$ & $-6,29$ & 0,06 & $-105,50$ & $<0,0001$ \\
\hline
\end{tabular}

Nota. Para a tabela da estimação dos parâmetros de escala $\left(\log \left(\sigma_{i}\right)\right)$ e forma $\left(\left(v_{i}\right)\right)$, favor consultar o Apêndice B.

Para a região, constatou-se que os estudantes da região Norte (baseline) obtiveram notas inferiores aos de outras regiões. Especificamente, a nota média dos alunos da região Norte foi inferior a dos discentes das regiões Nordeste, Sudeste, Sul e Centro-Oeste em 1,20, 2,95, 2,90 e 1,38 pontos, respectivamente. Além disso, alunos do EaD tiraram, em média, 6,80 pontos a menos do que os do presencial. Deste modo, as evidências relativas à modalidade de ensino desta pesquisa reforçam a visão de que estudantes do ensino presencial têm performance superior aos do EaD. E, finalmente, enquanto estudantes dos turnos integral tiraram, em média, 2,92 pontos a mais do que os do matutino, os do período noturno tiraram, 2,46 pontos a menos do que os do período da manhã. Estudantes do período vespertino desempenharam tão bem quanto os da manhã, visto que não houve diferença estatisticamente material $(\mathrm{p}>0,05)$.

\subsection{Discussão dos achados}

Nesta subseção, os resultados são discutidos com a literatura prévia levando-se em conta, também, as hipóteses formuladas. A hipótese 1 prediz que há diferença significante entre o desempenho de alunos matriculados nas distintas formas de organização acadêmica. De acordo com os resultados, a hipótese 1 foi sustentada. Foi possível verificar diferenças significativas de desempenho entre as cinco categorias da variável OAC. Para as três formas de mensuração do desempenho (DEF, DFG e DCE), a melhor nota foi obtida por alunos de Cefets, seguidos pelos de IFs, universidades, centros universitários e faculdades. Visto que as IES podem se organizar academicamente de diferentes maneiras, é importante que estudos futuros investiguem de forma 
detalhada quais características são as mais influentes em se tratando de performance de seus alunos.

Os resultados do presente trabalho são opostos aos de Bervian e Corrêa (2015) no sentido de que estes não encontraram diferenças relevantes entre os desempenhos de alunos matriculados em universidades, faculdades e centros universitários. Por outro lado, os achados de Caetano et al. (2015) mostraram que há diferença significativa entre o desempenho de discentes de universidades e de outras formas de organização acadêmica (não-universidade). Aqueles obtiveram melhores performances do que estes. Ainda, o estudo de Santos (2012) aponta que, para o Provão 2002, a organização acadêmica não foi variável relevante para explicar o desempenho discente. Entretanto, no Provão 2003 e no Enade 2006, foi significativa, favorecendo os estudantes matriculados em universidades e centros universitários. Diferentemente de estudos prévios que agruparam as categorias de organização acadêmica, o presente trabalho analisa as categorias isoladamente, provendo achados mais específicos. Um achado novo é referente ao Cefet, pouco mencionado pela literatura consultada e cujos estudantes apresentaram o melhor desempenho segundo as análises da presente pesquisa. Apesar disso, reporta-se que este achado deve ser visto com cautela devido ao baixo número de observações. Mesmo assim, é um ponto que merece maior aprofundamento e que levanta algumas questões, tais como: quais são as políticas de incentivo dos Cefets para que os estudantes se sintam mais motivados ao fazer o Enade? Quais práticas pedagógicas diferenciadas os docentes estão usando nos Cefets? Baldo (2018) aponta que os Cefets atuam na educação profissional pós-secundária visando a qualificação profissional nos múltiplos níveis de educação e que fazem uso das diferentes modalidades de ensino disponíveis. Será que este tipo de qualificação ou de educação profissional apresenta características fundamentalmente distintas dos cursos de graduação tradicionais em administração e contabilidade? Se sim, que características e por que afetam o desempenho de forma mais positiva do que em outros tipos de organização acadêmica? Estudos futuros podem olhar mais de perto os Cefets com o intuito de responder tais questões.

A hipótese 2 determina que as regiões Norte e Nordeste estão negativamente associadas ao desempenho acadêmico. Os resultados da presente pesquisa oferecem sustentação parcial à H2. A região Norte, dentre todas as regiões, apresentou o pior desempenho final (DEF) e o pior desempenho na prova de componente específico (DCE). A única situação em que a região Norte obteve melhor nota foi no caso da prova de formação geral (DFG), em relação ao Centro-Oeste. Portanto, tomados em conjunto, estes achados corroboram o que foi predito pela H2. Entretanto, a região Nordeste obteve nota superior à do Centro-Oeste em se tratando do desempenho final (DEF) e do desempenho na prova de formação geral (DFG). O Centro-Oeste superou o Nordeste somente nas questões de componente específico (DCE). Portanto, a região Nordeste ficou atrás apenas das regiões Sul e Sudeste.

Os dados da PNAD Contínua - Educação 2019 (IBGE, 2019) mostram múltiplos quesitos educacionais em que a região Nordeste é deficitária em relação às demais. Os dados analisados por Santos et al. (2014) indicam que os dez estados com a menor renda per capita pertencem às regiões Norte e Nordeste. Apesar destas diferenças econômicas, sociais e educacionais entre as regiões, o Nordeste ainda conseguiu superar o Centro-Oeste. Por este motivo, a região Nordeste parece não estar associada a uma nota tão negativa quanto se poderia pensar e, consequentemente, a $\mathrm{H} 2$ está somente parcialmente sustentada. Em suma e de forma geral (DEF), a liderança do desempenho ficou com a região Sul, seguida da região Sudeste, Nordeste, Centro-oeste e Norte. Este resultado é consistente com os de Mallmann et al. (2021), Santos (2012) e Brandt et al. (2020), os quais evidenciam que as regiões Sul e Sudeste se sobressaíram em relação às demais. Por outro lado, diferencia-se do estudo de Nasu e Sasso (2021), os quais identificaram que o melhor desempenho ficou com a região Nordeste, seguida da Sudeste, Norte, 
Centro-Oeste e Sul. Esta diferenciação de resultado pode estar associada aos cursos considerados nas análises das pesquisas. $\mathrm{O}$ presente trabalho abarcou somente alunos de ciências contábeis e administração, enquanto o de Nasu e Sasso (2021) incluiu, além destes, o de economia, secretariado executivo e turismo.

A hipótese 3 estabelece que há relação positiva entre o ensino presencial e o desempenho acadêmico. Os resultados para as três formas de mensuração do desempenho oferecem forte amparo à H3. Os alunos do ensino presencial tiraram, em média, 6,36, 5,28 e 6,80 pontos a mais do que os do EaD no caso do DEF, DFG e DCE, respectivamente. Estas evidências sugerem que a modalidade presencial é de superior qualidade comparativamente ao formato a distância. A maior discrepância reside no DCE (6,80 pontos de diferença), indicando que os estudantes de ciências contábeis e administração do EaD precisam de maior atenção e auxílio nas questões de componente específico. Isto é, naqueles conteúdos que são específicos de suas profissões.

Os achados da presente pesquisa sustentam o questionamento por pesquisadores acerca da qualidade do EaD (Alonso, 2010; Bertolin, 2021), além de serem compatíveis com o resultado de Caetano et al. (2015). Adicionalmente, reforçam a visão de empregadores acerca da preferência por contratar funcionários que realizaram o curso de graduação presencialmente (Grossman \& Johnson, 2016), dado que estes têm apresentado desempenho superior aos do EaD. Apesar do baixo desempenho por parte dos alunos do $\mathrm{EaD}$, o presente trabalho não sugere que tal modalidade deva ser descontinuada. É melhor que haja a opção pelo EaD do que extingui-lo. No entanto, isto não o exime de questionamentos sobre a sua qualidade. É legítimo que a sociedade e os agentes acadêmicos continuem, constantemente, questionando e cobrando serviços educacionais de qualidade mais elevada tanto no EaD como no presencial. A pandemia de Covid-19 fez com que o ensino presencial migrasse para o ensino remoto, o qual também está sujeito a críticas de qualidade educacional, principalmente porque a transição do presencial para o remoto foi feita emergencialmente e alguns docentes podem não ter tido a preparação suficiente e apropriada para lidar com os equipamentos tecnológicos de ensino. Por outro lado, com a adoção do ensino remoto, todos passaram a aprender a distância, o que pode reduzir o nível de preferência por contratação de pessoas que realizaram os cursos de modo presencial.

A hipótese 4 define que o turno integral está associado positivamente ao desempenho acadêmico. Os resultados corroboram a $\mathrm{H} 4$ ao mostrar que os alunos do turno integral obtiveram as melhores notas nos três tipos de desempenho. Foi possível observar, para os três desempenhos também, que não houve diferença estatisticamente significante de performance entre os alunos dos turnos matutino e vespertino. Os estudantes do turno da noite, contudo, apresentaram notas significativamente inferiores do que os do matutino nas três formas de mensuração do desempenho, com atenção especial à nota de formação geral que foi na qual houve a maior diferença (3,59 pontos).

O resultado deste trabalho é compatível com a expectativa hipotetizada porque alunos do turno integral possuem mais tempo de estudo do que outros que possuem dedicação parcial. $\mathrm{O}$ achado é consistente com a pesquisa de Mallmann et al. (2021), os quais também encontraram que o turno integral obteve a melhor performance acadêmica. No caso de Farias et al. (2015), o turno integral não era um opção. Mas foi constatado que os alunos do turno diurno (manhã e tarde) performaram melhor do que os estudantes da noite. Os estudantes de cursos noturnos tendem a trabalhar durante o dia inteiro (Cornachione Junior et al., 2010), podendo chegar às aulas noturnas mais cansados e, potencialmente, com um nível de atenção mais deficitário. Muitos estudantes trabalham pelo próprio sustento ou por de sua família, tendo como única alternativa o curso noturno (Moura et al., 2015). Por esta razão, é particularmente recomendável aos docentes de cursos noturnos o uso de metodologias ativas de ensino com o propósito de promover maior envolvimento dos discentes nas aulas. 


\section{CONSIDERAÇÕES FINAIS}

O objetivo da presente pesquisa foi analisar a associação entre variáveis institucionais (organização acadêmica, região, modalidade e turno) e o desempenho acadêmico (desempenho final, desempenho na prova de formação geral e desempenho na prova de componente específico) de estudantes da área de negócios (administração e contabilidade). Coletaram-se os microdados referentes à edição do Enade 2018, obtendo-se 152.491 observações válidas. Os dados foram examinados a partir de modelos de regressão BCCG com zeros ajustados, os quais não apresentaram problemas de ajuste, conforme sugeriram as análises diagnósticas. Deste modo, aponta-se que esta forma de modelagem é candidata a ser utilizada em estudos futuros que apresentem dados com características similares aos deste estudo.

A partir dos resultados, conclui-se que as variáveis institucionais foram relevantes para explicar o desempenho dos estudantes. Foi observado que, em geral, estudantes matriculados em Cefets tiveram desempenho superior aos de universidades, centros universitários, faculdades e IFs. Outro ponto é que, para o desempenho final, os alunos da região Norte performaram pior do que o das outras regiões. Todavia, quando da análise por tipo de conteúdo, constatou-se que os alunos da região Norte superaram os da região Centro-Oeste nas questões de formação geral. Quanto à modalidade de ensino, verificou-se que alunos do ensino presencial apresentaram performance superior aos discentes do EaD. E estudantes do turno integral tiveram melhores performances de modo geral.

O presente estudo possui implicações para estudantes, professores e IES. No caso dos estudantes, os achados contribuem para uma melhor tomada de decisão quando da escolha da IES e da forma de aprendizagem. Para maximizar o desempenho acadêmico no Enade, é recomendável que o aluno opte pela modalidade de ensino presencial, pelo período integral, pela região Sul e pelo Cefet. Ressalta-se que esta última variável de IES deve ser vista com cautela, uma vez que houve poucas observações que estudaram em Cefets em comparação com às demais. Portanto, o aluno deve pesquisar e alinhar os seus objetivos à organização acadêmica da IES, priorizando as de superior qualidade e reputação.

Para docentes, as análises comparativas deste estudo podem promover maior encorajamento do aperfeiçoamento do ensino. Por exemplo, constatou-se que os alunos do ensino presencial têm melhores performances do que os do EaD. Neste sentido, os docentes do $\mathrm{EaD}$ podem querer disponibilizar materiais adicionais, incluir mais matérias optativas, considerar novas estratégias e equipamentos de ensino nas aulas etc. com o propósito de elevar a qualidade da educação dos futuros contadores e administradores. Complementarmente, frisa-se que a região Centro-Oeste obteve o pior desempenho nas questões de formação geral. Logo, é importante que os docentes dos cursos de contabilidade e administração do Centro-Oeste que lecionam matérias de competências gerais (ex.: comunicação, interpretação de texto, ética profissional, empreendedorismo) adotem novas e diferentes abordagens pedagógicas para fortificar o conhecimento de formação geral dos estudantes a fim de aumentar a sua performance. Foi constatado, também, que os estudantes do turno noturno obtiveram as piores performances. Cornachione Junior et al. (2010) apontam que estes alunos tipicamente trabalham durante todo o dia, o que pode levá-los a um maior nível de cansaço ao assistirem as aulas à noite. Nesse sentido, sugere-se aos docentes que atuam no período noturno a utilização de metodologias ativas de ensino, as quais possuem potencial de forte envolvimento do aluno no processo de aprendizagem.

Para as IES, este estudo possui duas sérias implicações. Primeiro, é importante reconhecer que os alunos obtiveram baixo desempenho no Enade. Como mostrou a Tabela 2, o desempenho médio final foi de 37,88 pontos em uma escala de 0,00 a 100,00 pontos. De posse 
deste resultado, além do aperfeiçoamento do ensino, as IES podem querer implantar políticas que incentivem os estudantes a performarem melhor, tal como a concessão de créditos adicionais ou horas de atividade complementar para aqueles que atingirem uma nota mínima sob o argumento de que foi necessária a dedicação de tempo de estudo extra para o Enade. Como discutido na Introdução, o desempenho discente no Enade é um dos critérios para classificar a qualidade das IES. Ao motivar os seus estudantes, a IES pode se beneficiar ao ter sua nota aumentada, o que, por sua vez, eleva a sua reputação perante o mercado e a sociedade. Segundo, ao evidenciar as categorias que reduzem o desempenho estudantil, as IES podem direcionar recursos para o seu aprimoramento. Por exemplo, as IES localizadas na região Norte ou que possuem campus nesta região podem querer investir mais em suas instalações, seus materiais e na qualificação de seus professores, dado que o desempenho de seus estudantes foi menor em comparação com as demais regiões. Do mesmo modo, as IES podem querer ofertar cursos de ciências contábeis e administração em período integral, visto que os estudantes deste turno obtiveram melhores notas comparativamente aos demais. Alerta-se, contudo, que esta oferta deve ser pensada minuciosamente por poder envolver custos relevantes.

A presente pesquisa possui limitações que merecem ser pontuadas. A primeira é que há pouca pesquisa sobre a relação entre a organização acadêmica das IES e o desempenho discente (Miranda et al., 2015). Logo, reconhece-se que a discussão teórica ficou mais restrita neste sentido. A segunda limitação é que algumas variáveis institucionais apresentaram desbalanceamento em termos de frequência de suas categorias, tais como OAC - Cefet, OAC IF e TUR - Vespertino. A esse respeito, reporta-se que os modelos de regressão continuaram adequados. Uma terceira limitação é o uso de dados do ano de 2018. Desde então, o cenário educacional sofreu mudanças relevantes, principalmente em decorrência da pandemia de Covid19. Apesar disso, enfatiza-se que o Enade 2018 foi a última edição realizada por alunos de ciências contábeis e administração cujos dados estão disponíveis.

Como recomendações de pesquisas futuras, sugere-se, além daquelas realizadas ao longo do trabalho, as seguintes: (i) inclusão de outras variáveis institucionais nos modelos; (ii) análise da relação entre variáveis institucionais e o desempenho discente por tipo de questão (ex.: discursiva vs. objetiva) e conteúdo programático (ex.: contabilidade de custos, contabilidade societária, administração financeira etc.) constantes nos currículos dos cursos da área de negócios; e (iii) exame do desempenho acadêmico quando há alteração de variável institucional. Por exemplo, quando um aluno de faculdade passa a estudar em uma universidade ou quando um aluno da região Sul passa a estudar na região Sudeste.

\section{REFERÊNCIAS}

Ahinful, G. S., Tauringana, V., Bansah, E. A., \& Essuman, D. (2019). Determinants of academic performance of accounting students in Ghanaian secondary and tertiary education institutions. Accounting Education, 28(6), 553-581. https://doi.org/10.1080/09639284.2019.1679204

Alonso, K. M. (2010). A expansão do ensino superior no Brasil e a EaD: dinâmicas e lugares. Educação \& Sociedade, 31, 1319-1335. https://doi.org/10.1590/S0101-73302010000400014

Andreoli, C. P. P., \& De Martino, M. M. F. (2012). Academic performance of night-shift students and its relationship with the sleep-wake cycle. Sleep Science, 5(2), 45-48. Recuperado de http://sleepscience.org.br/details/55/en-US/academic-performance-of-nightshift-students-and-its-relationship-with-the-sleep-wake-cycle 
Baldo, G. C. (2018). Educação superior brasileira: organização acadêmica. Revista Científica Eletrônica do Curso de Direito, 14, 1-21. Recuperado de http://faef.revista.inf.br/imagens_arquivos/arquivos_destaque/wkAntfKsLYEcp33_2019-228-15-25-49.pdf

Beatson, N., Gabriel, C.-A., Howell, A., Scott, S., van der Meer, J., \& Wood, L. C. (2020). Just opt in: How choosing to engage with technology impacts business students' academic performance. Journal of Accounting Education, 100641. https://doi.org/10.1016/j.jaccedu.2019.100641

Bertolin, J. C. G. (2021). Existe diferença de qualidade entre as modalidades presencial e a distância? Cadernos de Pesquisa, 51, e06958. https://doi.org/10.1590/198053146958

Bervian, L. M., \& Corrêa, M. (2015). ENADE: Impactos da categoria administrativa, organização acadêmica e número de participantes no desempenho dos estudantes. Revista de Administração Educacional, $\quad$ 1(2), 6-27. $\quad$ Recuperado de https://periodicos.ufpe.br/revistas/ADED/article/viewFile/2475/2003

Brandt, J. Z., Tejedo-Romero, F., \& Araujo, J. F. F. E. (2020). Fatores influenciadores do desempenho acadêmico na graduação em administração pública. Educação e Pesquisa, 46, e202500. https://doi.org/10.1590/s1678-4634202046202500

Byrne, M., \& Flood, B. (2008). Examining the relationships among background variables and academic performance of first year accounting students at an Irish University. Journal of Accounting Education, 26(4), 202-212. https://doi.org/10.1016/j.jaccedu.2009.02.001

Caetano, C., Cardoso, T., Miranda, G., \& Freitas, S. (2015). Academic performance in accounting: online versus traditional education. Revista Universo Contábil, 11(4), 147-165. https://doi.org/10.4270/ruc.2015436

Cheng, C., Sapkota, P., \& Yurko, A. J. N. (2021). A Case Study of Effective Tax Rates Using Data Analytics. Issues in Accounting Education, 36(1), 65-89. https://doi.org/10.2308/ISSUES-19-060

Cornachione Junior, E. B., Cunha, J. V. A. da, De Luca, M. M. M., \& Ott, E. (2010). O bom é meu, o ruim é seu: perspectivas da teoria da atribuição sobre o desempenho acadêmico de alunos da graduação em Ciências Contábeis. Revista Contabilidade \& Finanças, 21(53), 1-24. https://doi.org/10.1590/S1519-70772010000200004

Dunn, P. K., \& Smyth, G. K. (1996). Randomized Quantile Residuals. Journal of Computational and Graphical Statistics, 5(3), 236-244. https://doi.org/10.2307/1390802

ElKelish, W. W., \& Ahmed, R. (2021). Advancing accounting education using LEGO® Serious Play simulation technique. Accounting https://doi.org/10.1080/09639284.2021.1905011

Farias, M. R. S., Alves, F. de S., \& Farias, K. T. R. (2015). Desempenho acadêmico em métodos quantitativos nos cursos de Ciências Contábeis. Enfoque: Reflexão Contábil, 34(2), 37-50. https://doi.org/10.4025/enfoque.v34i2.26818 
Fogarty, T. J., Zimmerman, A. B., \& Richardson, V. J. (2016). What do we mean by accounting program quality? A decomposition of accounting faculty opinions. Journal of Accounting Education, 36, 16-42. https://doi.org/10.1016/j.jaccedu.2016.04.001

Fortin, A., Viger, C., Deslandes, M., Callimaci, A., \& Desforges, P. (2019). Accounting students' choice of blended learning format and its impact on performance and satisfaction. Accounting Education, 28(4), 353-383. https://doi.org/10.1080/09639284.2019.1586553

Francescucci, A., Kellershohn, J., \& Pyle, M. A. (2021). Using Online Class Preparedness Tools to Improve Student Performance: The Benefit of "All-In" Engagement. Journal of Management Education, 45(4), 558-578. https://doi.org/10.1177/1052562920960205

Gracia, L., \& Jenkins, E. (2003). A quantitative exploration of student performance on an undergraduate accounting programme of study. Accounting Education, 12(1), 15-32. https://doi.org/10.1080/0963928032000049375

Grimm, S. D. (2021). Junkyard Planet: Using Stories to Teach Managerial Accounting with a Sustainability Theme. Issues in Accounting Education. https://doi.org/10.2308/ISSUES-19063

Grossman, A. M., \& Johnson, L. R. (2016). Employer Perceptions of Online Accounting Degrees. Issues in Accounting Education, 31(1), 91-109. https://doi.org/10.2308/iace-51229

Grossman, A. M., \& Johnson, L. R. (2017). How employers perceive online accounting education: Evidence from Kentucky. Journal of Accounting Education, 40, 19-31. https://doi.org/10.1016/j.jaccedu.2017.06.002

IBGE. (2019). PNAD Educação 2019, PNAD Contínua. Recuperado de: https://biblioteca.ibge.gov.br/visualizacao/livros/liv101736_informativo.pdf

INEP. (2021). Microdados do Exame Nacional de Desempenho dos Estudantes. Recuperado em 12 agosto, 2021 de https://www.gov.br/inep/pt-br/acesso-a-informacao/dadosabertos/microdados/enade

Kafaji, M. (2020). The perceived benefits of accreditation on students' performance: The case of private business schools. Industry and Higher Education, 34(6), 421-428. https://doi.org/10.1177/0950422220902698

Kuang, T. M., Adler, R. W., \& Pandey, R. (2021). Creating a Modified Monopoly Game for Promoting Students' Higher-Order Thinking Skills and Knowledge Retention. Issues in Accounting Education, 36(3), 49-74. https://doi.org/10.2308/ISSUES-2020-097

Madsen, P. E. (2020). Research Initiatives in Accounting Education: Transforming Today's Students into Accounting Professionals. Issues in Accounting Education, 35(4), 35-46. https://doi.org/10.2308/ISSUES-2020-016

Mallmann, C., Nasu, V., \& Domingues, M. J. (2021). Relação entre a leitura de livros e o desempenho acadêmico: análise com discentes de ciências sociais aplicadas. Revista de 
Educação e Pesquisa Em Contabilidade (REPeC), $15(2), \quad$ 163-184. https://doi.org/10.17524/repec.v15i2.2751

McCarthy, M., Kusaila, M., \& Grasso, L. (2019). Intermediate accounting and auditing: Does course delivery mode impact student performance? Journal of Accounting Education, 46, 2642. https://doi.org/10.1016/j.jaccedu.2018.12.001

Miglietti, C. (2021). Student performance in accounting courses: Do bonus points motivate performance? Journal of Education for Business, 96(4), 237-242. https://doi.org/10.1080/08832323.2020.1812486

Miranda, G. J., Lemos, K. C. da S., Oliveira, A. S. de, \& Ferreira, M. A. (2015). Determinantes do Desempenho Acadêmico na Área de Negócios. Revista Meta: Avaliação, 7(20), 175-209. https://doi.org/10.22347/2175-2753v7i20.264

Moura, A. C. da R., Miranda, G. J., \& Pereira, J. M. (2015). Desempenho acadêmico em ciências contábeis: turno noturno versus diurno. Enfoque: Reflexão Contábil, 34(1), 57-70. https://doi.org/10.4025/enfoque.v34i1.23020

Nakos, G., \& Whiting, A. (2018). The role of frequent short exams in improving student performance in hybrid global business classes. Journal of Education for Business, 93(2), 5157. https://doi.org/10.1080/08832323.2017.1417231

Namin, A., Ketron, S. C., Kaltcheva, V. D., \& Winsor, R. D. (2021). Improving Student Presentation Skills Using Asynchronous Video-Based Projects. Journal of Management Education, 45(6), 987-1010. https://doi.org/10.1177/1052562920978805

Nasu, V. H. (2020). Accounting students' performance in distance education: a study focused on sociodemographic factors. Journal of Information Systems and Technology Management, 17, e202017007. https://doi.org/10.4301/S1807-1775202017007

Nasu, V. H., \& Sasso, M. (2021). A Bolsa faz Diferença? Uma Análise do Desempenho Acadêmico de Alunos Bolsistas de Cursos de Graduação da Área de Negócios. Arquivos $\begin{array}{lllll}\text { Analíticos de Políticas } & \text { Educativas, } & \text { 29(99), }\end{array}$ https://doi.org/https://doi.org/10.14507/epaa.29.5896

Nsor-Ambala, R. (2020). Impact of exam type on exam scores, anxiety, and knowledge retention in a cost and management accounting course. Accounting Education, 29(1), 32-56. https://doi.org/10.1080/09639284.2019.1683871

Pike, G. R. (1991). The effects of background, coursework, and involvement on students' grades and satisfaction. Research in Higher Education, 32(1), 15-30. https://doi.org/10.1007/BF00992830

R Core Team. (2020). R: a language and environment for statistical computing. Vienna, AT: R Foundation for Statistical Computing. 
Rigby, R., Stasinopoulos, M. D., Heller, G. Z., \& De Bastiani, F. (2019). Distributions for modeling location, scale, and shape: Using GAMLSS in R. Chapman \& Hall/CRC The $\mathrm{R}$ Series.

Rodrigues, B., Miranda, G., Resende, M., \& Pereira, J. (2016). Determinantes do desempenho acadêmico dos alunos dos cursos de Ciências Contábeis no ensino à distância. Enfoque: Reflexão Contábil, 35(2), 139-153. https://doi.org/10.4025/enfoque.v35i2.30105

Santos, N. A. (2012). Determinantes do desempenho acadêmico dos alunos dos cursos de ciências contábeis. [Tese de doutorado, Faculdade de Economia, Administração e Contabilidade da Universidade de São Paulo]. Biblioteca Digital USP. https://doi.org/10.11606/T.12.2012.tde-11062012-164530

Santos, G. R., Pales, R. C., \& Rodrigues, S. G. (2014). Desigualdades regionais no Brasil 1991-2010. InterSciencePlace - Revista Científica Internacional, 31(1), Artigo 6. https://doi.org/10.6020/1679-9844/3106

SAS Institute. (1996). Statistical Analysis System Institute (Cary, \& NC).

Soares, J. (2004). O efeito da escola no desempenho cognitivo de seus alunos. Revista Iberoamericana sobre Calidad, Eficacia y Cambio em Educación, 2(2), 83-104. Recuperado de: https://revistas.uam.es/reice/article/view/5550

Stasinopoulos, D. M., Enea, M., \& Rigby, R. A. (2017). Zero adjusted distributions on the positive real line. Recuperado de http://www.gamlss.com/wpcontent/uploads/2018/01/ZeroAdjustedDistributions.pdf

Stasinopoulos, D. M., Rigby, R., Voudouris, V., Akantziliotou, C., Enea, M., \& Kiose, D. (2021). Package 'gamlss.' CRAN. Recuperado de https://cran.rproject.org/web/packages/gamlss/gamlss.pdf

Stice, E. K., Stice, J. D., \& Albrecht, C. (2020). Study Choices by Introductory Accounting Students: Those Who Study More Do Better and Text Readers Outperform Video Watchers. In Advances in Accounting Education: Teaching and Curriculum Innovations (Vol. 24, pp. 3 29). https://doi.org/10.1108/S1085-462220200000024007

Taylor, M., Marrone, M., Tayar, M., \& Mueller, B. (2017). Digital storytelling and visual metaphor in lectures: a study of student engagement. Accounting Education, 1-18. https://doi.org/10.1080/09639284.2017.1361848

Westerman, J. W., Whitaker, B. G., Bergman, J. Z., Bergman, S. M., \& Daly, J. P. (2016). Faculty narcissism and student outcomes in business higher education: A student-faculty fit analysis. The International Journal of Management Education, 14(2), 63-73. https://doi.org/10.1016/j.ijme.2016.02.001

\section{APÊNDICE A}

Este apêndice reporta os resultados da qualidade do ajuste dos modelos de regressão aos dados. 
i) Modelo BCCG com zeros ajustados: desempenho final (DEF)

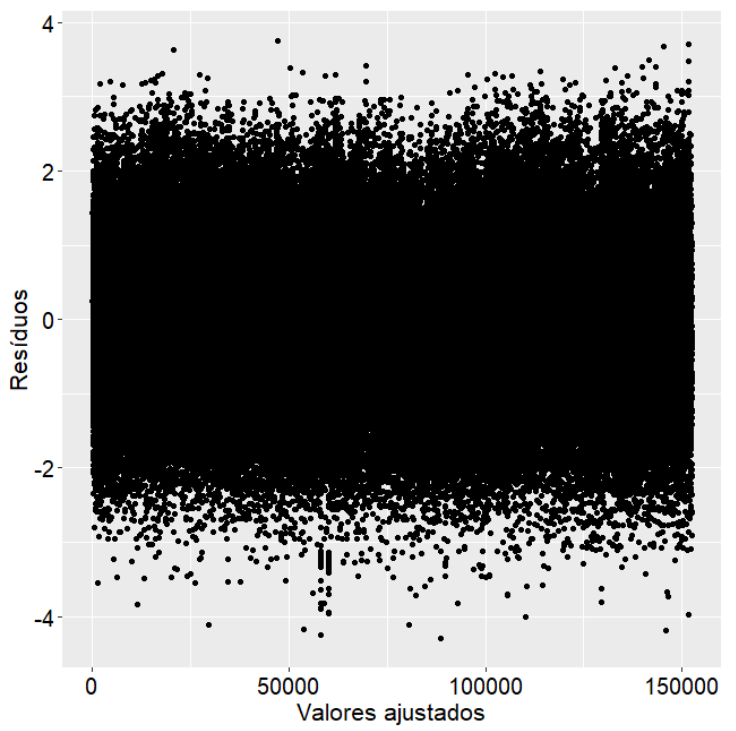

A - Valores ajustados vs. resíduos quantílicos aleatorizados

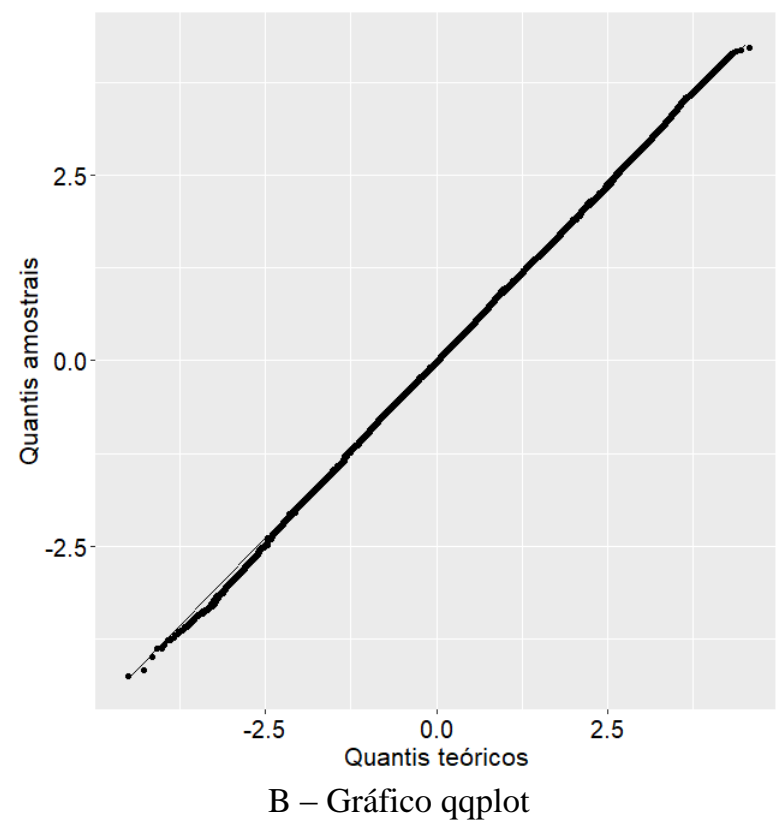

ii) Modelo BCCG com zeros ajustados: desempenho na prova de formação geral (DFG)

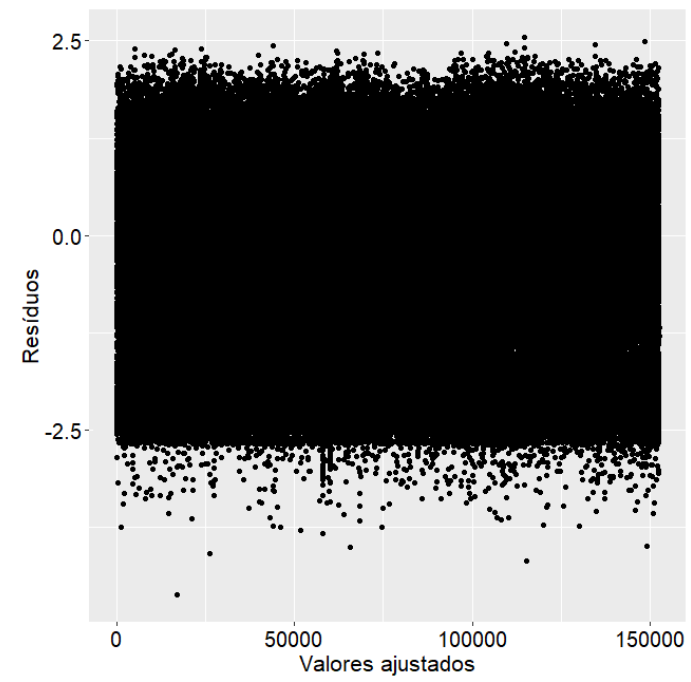

A - Valores ajustados vs. resíduos quantílicos aleatorizados

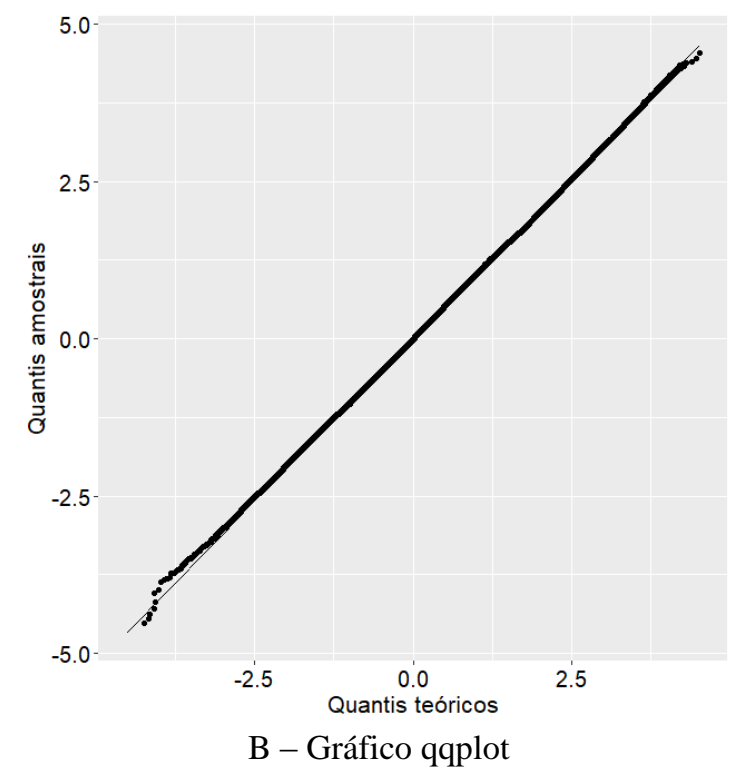

iii) Modelo BCCG com zeros ajustados: desempenho na prova de componente específico (DCE) 


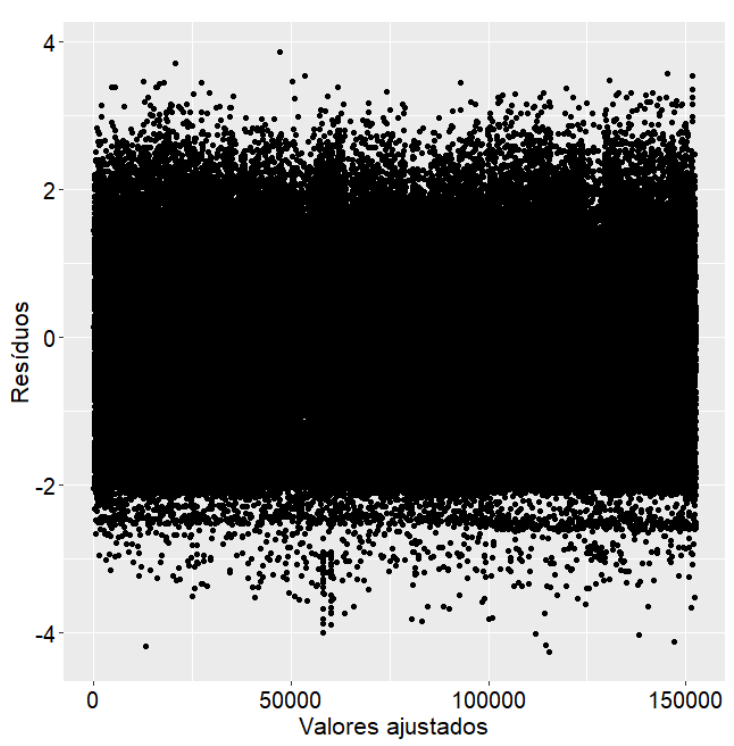

A - Valores ajustados vs. resíduos quantílicos aleatorizados

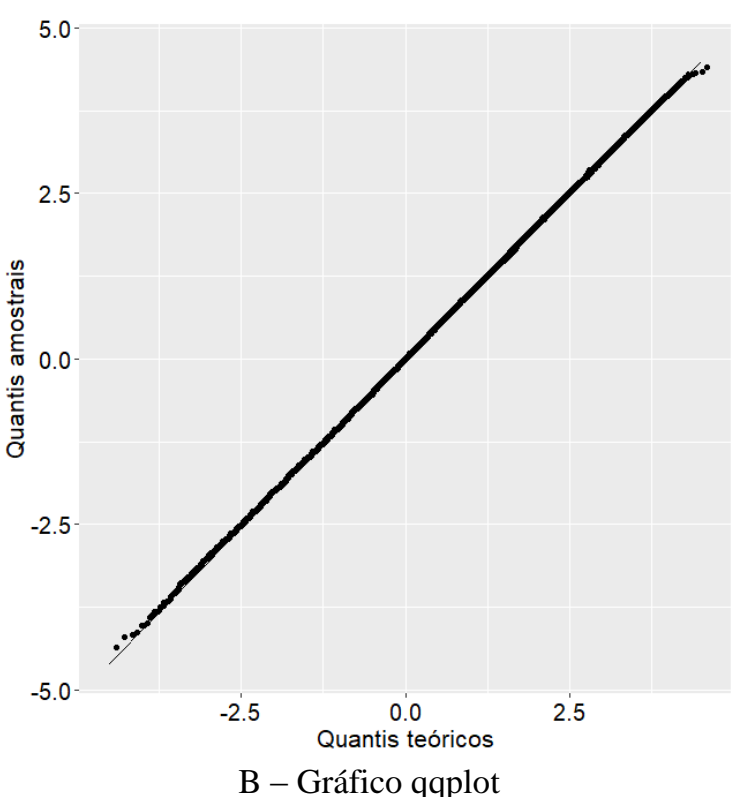

B - Gráfico qqplot

\section{APÊNDICE B}

Este apêndice reporta os resultados dos modelos de regressão dos parâmetros de escala $\left(\log \left(\sigma_{i}\right)\right)$ e forma $\left(v_{i}\right)$, os quais fornecem, respectivamente, indicação de potenciais diferenças entre as variâncias e entre as simetrias dos desempenhos.

Parâmetro de escala (DEF, DFG e DCE)

Resultado do modelo BCCG com zeros ajustados (parâmetro $\left(\log \left(\sigma_{i}\right)\right)$ para o DEF

\begin{tabular}{lcccc}
\hline DEF & Estimativa & Erro-padrão & Estatística t & Valor-p \\
\hline (Intercepto) & $-1,4$ & 0,1 & $-20,4$ & $<0,0001^{* * *}$ \\
OAC - CUniv & 0,3 & 0,1 & 3,9 & $<0,0001^{* * *}$ \\
OAC - Faculdade & 0,3 & 0,1 & 4,0 & $<0,0001^{* * *}$ \\
OAC - IF & 0,2 & 0,1 & 2,7 & $<0,0001^{* * *}$ \\
OAC - Universidade & 0,3 & 0,1 & 3,9 & $<0,0001^{* * *}$ \\
REG - Nordeste & 0,0 & 0,0 & 3,1 & $<0,0001^{* * *}$ \\
REG - Sudeste & 0,0 & 0,0 & 2,8 & $<0,0001^{* * *}$ \\
REG - Sul & 0,0 & 0,0 & 1,1 & 0,2899 \\
REG - Centro-Oeste & 0,0 & 0,0 & 3,4 & $<0,0001^{* * *}$ \\
MOD - EaD & 0,1 & 0,0 & 12,3 & $<0,0001^{* * *}$ \\
TUR - Vespertino & 0,0 & 0,0 & 0,9 & 0,3752 \\
TUR - Integral & 0,0 & 0,0 & $-2,0$ & $0,0489^{* * *}$ \\
TUR - Noturno & 0,0 & 0,0 & 2,6 & $0,0102^{* * *}$ \\
\hline
\end{tabular}

Resultado do modelo BCCG com zeros ajustados (parâmetro $\left(\log \left(\sigma_{i}\right)\right.$ ) para o DFG

\begin{tabular}{lcccc}
\hline DFG & Estimativa & Erro-padrão & Estatística $\boldsymbol{t}$ & Valor-p \\
\hline (Intercepto) & $-1,10$ & 0,36 & $-3,07$ & $0,0020^{* * *}$ \\
OAC - CUniv & 0,07 & 0,36 & 0,20 & 0,8413 \\
OAC - Faculdade & 0,10 & 0,36 & 0,28 & 0,7777 \\
OAC - IF & 0,01 & 0,36 & 0,03 & 0,978 \\
OAC - Universidade & 0,05 & 0,36 & 0,14 & 0,8917
\end{tabular}




\begin{tabular}{|c|c|c|c|c|}
\hline REG - Nordeste & 0,02 & 0,01 & 1,88 & 0,0606 \\
\hline REG - Sudeste & 0,02 & 0,02 & 2,30 & $0,0216^{* * *}$ \\
\hline REG - Sul & 0,00 & 0,01 & $-0,01$ & 0,9945 \\
\hline REG - Centro-Oeste & 0,06 & 0,01 & 4,60 & $<0,0001 * * *$ \\
\hline $\mathrm{MOD}-\mathrm{EaD}$ & 0,06 & 0,01 & 10,99 & $<0,0001 * * *$ \\
\hline TUR - Vespertino & $-0,01$ & 0,02 & $-0,42$ & 0,678 \\
\hline TUR - Integral & $-0,04$ & 0,01 & $-3,34$ & $<0,0001 * * *$ \\
\hline TUR - Noturno & 0,03 & 0,01 & 3,68 & $<0,0001 * * *$ \\
\hline
\end{tabular}

Resultado do modelo BCCG com zeros ajustados (parâmetro $\left(\log \left(\sigma_{i}\right)\right)$ para o DCE

\begin{tabular}{|c|c|c|c|c|}
\hline DCE & Estimativa & Erro-padrão & Estatística $t$ & Valor-p \\
\hline (Intercepto) & $-1,23$ & 0,07 & $-18,16$ & $<0,0001 * * *$ \\
\hline OAC - CUniv & 0,23 & 0,07 & 3,48 & $0,0005 * * *$ \\
\hline OAC - Faculdade & 0,25 & 0,07 & 3,78 & $0,0001 * * *$ \\
\hline $\mathrm{OAC}-\mathrm{IF}$ & 0,18 & 0,08 & 2,32 & $0,0202 * * *$ \\
\hline OAC - Universidade & 0,24 & 0,07 & 3,61 & 0,0003 \\
\hline REG - Nordeste & 0,02 & 0,01 & 1,71 & 0,0873 \\
\hline REG - Sudeste & 0,00 & 0,01 & $-0,44$ & 0,6637 \\
\hline $\mathrm{REG}-\mathrm{Sul}$ & $-0,01$ & 0,01 & $-1,33$ & 0,1842 \\
\hline REG - Centro-Oeste & 0,00 & 0,01 & 0,36 & 0,7208 \\
\hline $\mathrm{MOD}-\mathrm{EaD}$ & 0,09 & 0,01 & 15,71 & $<0,0001 * * *$ \\
\hline TUR - Vespertino & 0,02 & 0,02 & 0,92 & 0,3582 \\
\hline TUR - Integral & $-0,03$ & 0,01 & $-2,43$ & $0,0149 * * *$ \\
\hline TUR - Noturno & 0,02 & 0,01 & 2,97 & $0,0029 * * *$ \\
\hline
\end{tabular}

Parâmetro de forma (DEF, DFG e DCE)

Resultado do modelo BCCG com zeros ajustados (parâmetro $\left(v_{i}\right)$ para o DEF

\begin{tabular}{|c|c|c|c|c|}
\hline DEF & Estimativa & Erro-padrão & Estatística $t$ & Valor-p \\
\hline (Intercepto) & 1,20 & 0,35 & 3,48 & $<0,0001 * * *$ \\
\hline OAC - CUniv & $-0,38$ & 0,34 & $-1,09$ & 0,2737 \\
\hline OAC - Faculdade & $-0,44$ & 0,34 & $-1,27$ & 0,2046 \\
\hline $\mathrm{OAC}-\mathrm{IF}$ & $-0,19$ & 0,36 & $-0,54$ & 0,5913 \\
\hline OAC - Universidade & $-0,36$ & 0,34 & $-1,04$ & 0,297 \\
\hline REG - Nordeste & 0,02 & 0,03 & 0,64 & 0,5199 \\
\hline REG - Sudeste & 0,02 & 0,03 & 0,52 & 0,6008 \\
\hline REG - Sul & 0,06 & 0,03 & 1,75 & 0,0809 \\
\hline REG - Centro-Oeste & $-0,01$ & 0,04 & $-0,28$ & 0,7815 \\
\hline $\mathrm{MOD}-\mathrm{EaD}$ & $-0,21$ & 0,02 & $-12,78$ & $<0,0001 * * *$ \\
\hline TUR - Vespertino & 0,02 & 0,06 & 0,30 & 0,7633 \\
\hline TUR - Integral & 0,14 & 0,03 & 4,03 & $<0,0001 * * *$ \\
\hline TUR - Noturno & $-0,06$ & 0,02 & $-2,40$ & $0,0162 * * *$ \\
\hline
\end{tabular}

Resultado do modelo BCCG com zeros ajustados (parâmetro $\left(v_{i}\right)$ para o DFG

\begin{tabular}{lcccc}
\hline DFG & Estimativa & Erro-padrão & Estatística $\boldsymbol{t}$ & Valor-p \\
\hline (Intercepto) & 2,59 & 0,55 & 4,72 & $<0,0001^{* * *}$ \\
OAC - CUniv & $-1,54$ & 0,55 & $-2,82$ & $0,0048^{* * *}$ \\
OAC - Faculdade & $-1,61$ & 0,55 & $-2,95$ & $0,0031^{* * *}$ \\
OAC - IF & $-1,52$ & 0,56 & $-2,73$ & $0,0063 * * *$ \\
OAC - Universidade & $-1,49$ & 0,55 & $-2,72$ & $0,0065^{* * *}$ \\
REG - Nordeste & 0,02 & 0,04 & 0,58 & 0,5614 \\
REG - Sudeste & $-0,05$ & 0,04 & $-1,30$ & 0,1921 \\
\end{tabular}




\begin{tabular}{lcccc} 
REG - Sul & $-0,01$ & 0,04 & $-0,19$ & 0,8499 \\
REG - Centro-Oeste & $-0,05$ & 0,04 & $-1,24$ & 0,2168 \\
MOD - EaD & $-0,20$ & 0,02 & $-10,42$ & $<0,0001^{* * *}$ \\
TUR - Vespertino & $-0,06$ & 0,08 & $-0,72$ & 0,4741 \\
TUR - Integral & 0,18 & 0,05 & 3,49 & $0,0004^{* * *}$ \\
TUR - Noturno & $-0,13$ & 0,03 & $-3,93$ & $<0,0001^{* * *}$ \\
\hline
\end{tabular}

Resultado do modelo BCCG com zeros ajustados (parâmetro $\left(v_{i}\right)$ para o DCE

\begin{tabular}{|c|c|c|c|c|}
\hline DCE & Estimativa & Erro-padrão & Estatística $t$ & Valor-p \\
\hline (Intercepto) & 0,98 & 0,27 & 3,67 & $<0,0001 * * *$ \\
\hline OAC - CUniv & $-0,09$ & 0,27 & $-0,36$ & 0,7225 \\
\hline OAC - Faculdade & $-0,16$ & 0,27 & $-0,61$ & 0,5416 \\
\hline $\mathrm{OAC}-\mathrm{IF}$ & 0,28 & 0,33 & 0,85 & 0,3982 \\
\hline OAC - Universidade & $-0,07$ & 0,27 & $-0,25$ & 0,8006 \\
\hline REG - Nordeste & 0,05 & 0,03 & 1,75 & 0,0803 \\
\hline REG - Sudeste & 0,04 & 0,03 & 1,54 & 0,1229 \\
\hline REG - Sul & 0,07 & 0,03 & 2,46 & $0,0139 * * *$ \\
\hline REG - Centro-Oeste & 0,03 & 0,03 & 0,74 & 0,457 \\
\hline $\mathrm{MOD}-\mathrm{EaD}$ & $-0,19$ & 0,02 & $-12,11$ & $<0,0001 * * *$ \\
\hline TUR - Vespertino & $-0,02$ & 0,07 & $-0,29$ & 0,7701 \\
\hline TUR - Integral & 0,11 & 0,03 & 3,11 & $0,0018 * * *$ \\
\hline TUR - Noturno & $-0,06$ & 0,02 & $-2,68$ & $0,0073 * * *$ \\
\hline
\end{tabular}

